\title{
Organic peroxy radical chemistry in oxidation flow reactors and environmental chambers and their atmospheric relevance
}

\author{
Zhe Peng $^{1}$, Julia Lee-Taylor ${ }^{1,2}$, John J. Orlando ${ }^{2}$, Geoffrey S. Tyndall ${ }^{2}$, and Jose L. Jimenez ${ }^{1}$ \\ ${ }^{1}$ Cooperative Institute for Research in Environmental Sciences and Department of Chemistry, University of Colorado, \\ Boulder, Colorado 80309, USA \\ ${ }^{2}$ Atmospheric Chemistry Observation and Modeling Laboratory, National Center for Atmospheric Research, \\ Boulder, Colorado 80307, USA
}

Correspondence: Zhe Peng (zhe.peng@colorado.edu) and Jose L. Jimenez (jose.jimenez@colorado.edu)

Received: 9 September 2018 - Discussion started: 24 September 2018

Revised: 16 December 2018 - Accepted: 8 January 2019 - Published: 22 January 2019

\begin{abstract}
Oxidation flow reactors (OFRs) are a promising complement to environmental chambers for investigating atmospheric oxidation processes and secondary aerosol formation. However, questions have been raised about how representative the chemistry within OFRs is of that in the troposphere. We investigate the fates of organic peroxy radicals $\left(\mathrm{RO}_{2}\right)$, which play a central role in atmospheric organic chemistry, in OFRs and environmental chambers by chemical kinetic modeling and compare to a variety of ambient conditions to help define a range of atmospherically relevant OFR operating conditions. For most types of $\mathrm{RO}_{2}$, their bimolecular fates in OFRs are mainly $\mathrm{RO}_{2}+\mathrm{HO}_{2}$ and $\mathrm{RO}_{2}+\mathrm{NO}$, similar to chambers and atmospheric studies. For substituted primary $\mathrm{RO}_{2}$ and acyl $\mathrm{RO}_{2}, \mathrm{RO}_{2}+\mathrm{RO}_{2}$ can make a significant contribution to the fate of $\mathrm{RO}_{2}$ in OFRs, chambers and the atmosphere, but $\mathrm{RO}_{2}+\mathrm{RO}_{2}$ in OFRs is in general somewhat less important than in the atmosphere. At high $\mathrm{NO}, \mathrm{RO}_{2}+\mathrm{NO}$ dominates $\mathrm{RO}_{2}$ fate in OFRs, as in the atmosphere. At a high UV lamp setting in OFRs, $\mathrm{RO}_{2}+\mathrm{OH}$ can be a major $\mathrm{RO}_{2}$ fate and $\mathrm{RO}_{2}$ isomerization can be negligible for common multifunctional $\mathrm{RO}_{2}$, both of which deviate from common atmospheric conditions. In the OFR254 operation mode (for which $\mathrm{OH}$ is generated only from the photolysis of added $\mathrm{O}_{3}$ ), we cannot identify any conditions that can simultaneously avoid significant organic photolysis at $254 \mathrm{~nm}$ and lead to $\mathrm{RO}_{2}$ lifetimes long enough $(\sim 10 \mathrm{~s})$ to allow atmospherically relevant $\mathrm{RO}_{2}$ isomerization. In the OFR185 mode (for which $\mathrm{OH}$ is generated from reactions initiated by $185 \mathrm{~nm}$ photons), high relative humidity, low UV intensity and low precursor concentrations are recom-
\end{abstract}

mended for the atmospherically relevant gas-phase chemistry of both stable species and $\mathrm{RO}_{2}$. These conditions ensure minor or negligible $\mathrm{RO}_{2}+\mathrm{OH}$ and a relative importance of $\mathrm{RO}_{2}$ isomerization in $\mathrm{RO}_{2}$ fate in OFRs within $\sim \times 2$ of that in the atmosphere. Under these conditions, the photochemical age within OFR185 systems can reach a few equivalent days at most, encompassing the typical ages for maximum secondary organic aerosol (SOA) production. A small increase in OFR temperature may allow the relative importance of $\mathrm{RO}_{2}$ isomerization to approach the ambient values. To study the heterogeneous oxidation of SOA formed under atmospherically relevant OFR conditions, a different UV source with higher intensity is needed after the SOA formation stage, which can be done with another reactor in series. Finally, we recommend evaluating the atmospheric relevance of $\mathrm{RO}_{2}$ chemistry by always reporting measured and/or estimated $\mathrm{OH}, \mathrm{HO}_{2}, \mathrm{NO}, \mathrm{NO}_{2}$ and $\mathrm{OH}$ reactivity (or at least precursor composition and concentration) in all chamber and flow reactor experiments. An easy-to-use $\mathrm{RO}_{2}$ fate estimator program is included with this paper to facilitate the investigation of this topic in future studies.

\section{Introduction}

Laboratory reactors are needed to isolate and study atmospheric chemical systems. Environmental chambers have been a major atmospheric chemistry research tool for decades (Cocker et al., 2001; Carter et al., 2005; Presto et al., 2005; Wang et al., 2011; Platt et al., 2013). Over the last 
few years, oxidation flow reactors (OFRs; see Appendix A for the meanings of the acronyms) (Kang et al., 2007) have emerged as a promising complement to chambers and are being used to investigate atmospheric oxidation processes, particularly volatile organic compound (VOC) oxidation and secondary organic aerosol (SOA) formation and aging (Kang et al., 2011; Lambe et al., 2015; Hu et al., 2016; Palm et al., 2016). These processes have air quality (Levy II, 1971), human health (Nel, 2005) and climate impacts (Stocker et al., 2014).

The most important advantage of OFRs is their ability to achieve relatively high photochemical ages (of the order of equivalent hours or days assuming an average ambient $\mathrm{OH}$ concentration of $1.5 \times 10^{6}$ molecules $\mathrm{cm}^{-3}$; Mao et al., 2009) in minutes instead of hours in chambers (Lambe et al., 2011). Rapid aging is usually achieved by highly active $\mathrm{HO}_{x}$ radical chemistry initiated by low-pressure Hg lamp emissions (185 and $254 \mathrm{~nm})$ (Li et al., 2015; Peng et al., 2015). This allows for shorter residence times in OFRs, thus reducing the relative importance of gas and particle losses to walls (Palm et al., 2016), which can be very important in Teflon chambers (Cocker et al., 2001; Matsunaga and Ziemann, 2010; Zhang et al., 2014; Krechmer et al., 2016). In addition, the lower costs and small size (volumes of the order of $10 \mathrm{~L}$ ) of OFRs allow for better portability. These, together with the ability to rapidly achieve high photochemical ages, are advantageous for field applications. These advantages of OFRs have led a number of atmospheric chemistry research groups (Lambe and Jimenez, 2018) to deploy them in field (Hu et al., 2016; Ortega et al., 2016; Palm et al., 2016, 2017), source (Ortega et al., 2013; Tkacik et al., 2014; Karjalainen et al., 2016; Link et al., 2016) and laboratory studies (Kang et al., 2011; Lambe et al., 2013; Richards-Henderson et al., 2016; Lim et al., 2017).

While the use of oxidation flow reactors is growing rapidly in the atmospheric chemistry community, some researchers have raised two concerns with regard to OFRs: (1) the chemical regime of OFRs may be unrealistic compared to the atmosphere, and (2) OFRs are derivative of flow reactors with a long tradition in atmospheric chemistry, especially for chemical kinetic measurements, and thus there is not much new to be discussed or analyzed in their chemistry. While it is true that OFRs follow the tradition of flow tubes used in atmospheric chemistry, they attempt to simulate a much more complex system all at once and typically use much longer residence times, and thus many fundamental and practical issues arise that have not been addressed before. The need to achieve longer effective photochemical ages within a short residence time can, however, lead to the occurrence of undesirable oxidation pathways.

To clarify this issue, a series of chemical kinetic modeling studies have been performed: Li et al. (2015) and Peng et al. (2015) established a radical chemistry and oxidation model whose predictions compare well against laboratory experiments and found that $\mathrm{OH}$ can be substantially sup- pressed by external $\mathrm{OH}$ reactants (e.g., $\mathrm{SO}_{2}, \mathrm{NO}_{x}$ and VOCs externally introduced into the reactor); Peng et al. (2016) identified a low water mixing ratio $\left(\mathrm{H}_{2} \mathrm{O}\right)$ and/or high external $\mathrm{OH}$ reactivity $\left(\mathrm{OHR}_{\text {ext }}\right.$, i.e., first-order $\mathrm{OH}$ loss rate constant contributed by external $\mathrm{OH}$ reactants) as conditions that can cause significant non-tropospheric VOC reactions (e.g., through photolysis at 185 and/or $254 \mathrm{~nm}$ ); Peng and Jimenez (2017) studied $\mathrm{NO}_{y}$ chemistry in OFRs and showed that high-NO conditions, under which organic peroxy radicals react more rapidly with $\mathrm{NO}$ than with $\mathrm{HO}_{2}$, can only be realized by simple NO injection in a very narrow range of physical conditions, whose application to investigating intermediate- and high-NO environments (e.g., urban area) is limited; Peng et al. (2018) thus evaluated a few new techniques to maintain high-NO conditions in OFRs and found the injection of percent-level $\mathrm{N}_{2} \mathrm{O}$ effective to achieve this goal.

While $\mathrm{HO}_{x}$ and $\mathrm{NO}_{y}$ chemistries have been extensively characterized in OFRs so far, organic peroxy radical $\left(\mathrm{RO}_{2}\right)$ chemistry has yet to be considered in detail, as previous studies have only considered the balance between $\mathrm{RO}_{2}+\mathrm{NO}$ vs. $\mathrm{RO}_{2}+\mathrm{HO}_{2}$. There has been some speculation that due to high $\mathrm{OH}$ concentrations in OFRs, $\mathrm{RO}_{2}$ concentration and lifetime might be significantly different from ambient values, leading to the dominance of $\mathrm{RO}_{2}$ self- and cross-reactions and the elimination of $\mathrm{RO}_{2}$ isomerization pathways (Crounse et al., 2013; Praske et al., 2018). Given the central role $\mathrm{RO}_{2}$ plays in atmospheric chemistry (Orlando and Tyndall, 2012; Ziemann and Atkinson, 2012) and the rapidly increasing use of OFRs, $\mathrm{RO}_{2}$ chemistry in OFRs needs to be studied in detail to characterize the similarities and differences between their reaction conditions and those in the ambient atmosphere and traditional atmospheric reaction chambers.

In this paper, we address this need via modeling. All major known fates of $\mathrm{RO}_{2}$ in OFRs will be investigated and compared with those in typical chamber cases and in the atmosphere. This comparison will provide insights into the atmospheric relevance of $\mathrm{RO}_{2}$ chemistry in atmospheric simulation reactors and allow for the selection of experimental conditions with atmospherically relevant $\mathrm{RO}_{2}$ chemistry in experimental planning.

\section{Methods}

Due to a variety of loss pathways of $\mathrm{RO}_{2}$ and a myriad of $\mathrm{RO}_{2}$ types, $\mathrm{RO}_{2}$ chemistry is of enormous complexity. We detail the $\mathrm{RO}_{2}$ production and loss pathways of interest in this study, the approximations used to simplify this complex problem and the steps to investigate it methodically. We briefly introduce the base OFR design and the model, which are described in detail elsewhere (Kang et al., 2007; Peng et al., 2015, 2018). 


\subsection{Potential aerosol mass oxidation flow reactor (PAM OFR)}

The concept of the base OFR design simulated in this study, the potential aerosol mass (PAM) reactor, was first introduced by Kang et al. (2007) The geometry of the most popular PAM OFR is a cylinder of $\sim 13 \mathrm{~L}$ volume. The PAM reactor we simulate is equipped with low-pressure $\mathrm{Hg}$ lamps (model no. 82-9304-03, BHK Inc.) emitting UV light at 185 and $254 \mathrm{~nm}$. When both 185 and $254 \mathrm{~nm}$ photons are used to generate $\mathrm{OH}$ (termed "OFR185"), water vapor photolysis at $185 \mathrm{~nm}$ produces $\mathrm{OH}$ and $\mathrm{HO}_{2}$. Recombination of $\mathrm{O}_{2}$ and $\mathrm{O}\left({ }^{3} \mathrm{P}\right)$, formed by $\mathrm{O}_{2}$ photolysis at $185 \mathrm{~nm}$, generates $\mathrm{O}_{3}$. $\mathrm{O}\left({ }^{1} \mathrm{D}\right)$, formed through $\mathrm{O}_{3}$ photolysis at $254 \mathrm{~nm}$, reacts with water vapor and produces additional $\mathrm{OH} .185 \mathrm{~nm}$ photons can be filtered by installing quartz sleeves around the lamps. This converts the reactor into "OFR254" mode, for which the photolysis of $\mathrm{O}_{3}$, which must be initially injected, is the only $\mathrm{OH}$ production route. The notation "OFR254-X" is used to specify the initial amount of injected $\mathrm{O}_{3}(X \mathrm{ppm})$ in OFR254. Lambe et al. (2017) and Peng et al. (2018) have shown that the initial injection of $\mathrm{N}_{2} \mathrm{O}$ is able to maintain up to tens of ppb NO in both OFR185 and OFR254. These modes are denoted "OFR185-i $\mathrm{N}_{2} \mathrm{O}$ " and "OFR254-X-iN $2 \mathrm{O}$ ", or more generally "OFR-iN $\mathrm{N}_{2} \mathrm{O}$ ”. In OFR254-iN $\mathrm{O}_{2} \mathrm{O}, \mathrm{O}\left({ }^{1} \mathrm{D}\right)$ generated from $\mathrm{O}_{3}$ photolysis reacts with $\mathrm{N}_{2} \mathrm{O}$ to generate $\mathrm{NO}$, while in OFR $185-\mathrm{iN}_{2} \mathrm{O}, \mathrm{O}\left({ }^{1} \mathrm{D}\right)$ is mainly supplied by $\mathrm{N}_{2} \mathrm{O}$ photolysis at $185 \mathrm{~nm}$ (Peng et al., 2018).

\section{2 $\mathrm{RO}_{2}$ production and loss pathways}

A single generic $\mathrm{RO}_{2}$ is adopted for modeling purposes to avoid the huge number of $\mathrm{RO}_{2}$ types that would complicate effective modeling and analysis. In OH-initiated VOC oxidation, $\mathrm{RO}_{2}$ is primarily produced via $\mathrm{VOC}+\mathrm{OH} \rightarrow \mathrm{R}$ $\left(+\mathrm{H}_{2} \mathrm{O}\right)$ followed by $\mathrm{R}+\mathrm{O}_{2} \rightarrow \mathrm{RO}_{2}$, where $\mathrm{R}$ is hydrocarbyl or oxygenated hydrocarbyl radical. Since the second step is extremely fast in air (Atkinson and Arey, 2003), the first step controls the $\mathrm{RO}_{2}$ production rate, which depends on $\mathrm{OH}$ concentration and $\mathrm{OHR}_{\text {ext }}$ due to VOCs $\left(\mathrm{OHR}_{\mathrm{VOC}}\right.$; see Appendix $\mathrm{B}$ for details). OHR $\mathrm{VOC}_{\mathrm{C}}$ also includes the contribution from oxidation intermediates of primary VOCs (e.g., methyl vinyl ketone and pinonic acid). When the information about oxidation intermediates is insufficient to calculate OHR $\mathrm{VOC}_{\text {, }}$ OHR due to primary VOCs is used instead as an approximant. $\mathrm{RO}_{2}$ production through other pathways, e.g., VOC ozonolysis and photolysis, is not considered, since all non$\mathrm{OH}$ pathways of VOC destruction only become significant at low $\mathrm{H}_{2} \mathrm{O}$ and/or high $\mathrm{OHR}_{\text {ext }}$ (Peng et al., 2016). These conditions lead to significant non-tropospheric VOC photolysis and thus are of little experimental interest.

Table 1 lists all known $\mathrm{RO}_{2}$ loss pathways. Among those, $\mathrm{RO}_{2}$ photolysis, $\mathrm{RO}_{2}+\mathrm{NO}_{3}$ and $\mathrm{RO}_{2}+\mathrm{O}_{3}$ are not included in this study, since they are minor or negligible in $\mathrm{OH}-$ dominated atmospheres, chambers and OFRs for the following reasons.

The first-order $\mathrm{RO}_{2}$ photolysis rate constant is of the order of $10^{-2} \mathrm{~s}^{-1}$ at the highest lamp setting in OFRs (KalafutPettibone et al., 2013) and of the order of $10^{-5} \mathrm{~s}^{-1}$ in the troposphere under the assumption of unity quantum yield (Klems et al., 2015), while $\mathrm{RO}_{2}$ reacts with $\mathrm{HO}_{2}$ at $>1 \mathrm{~s}^{-1}$ at the highest lamp setting in OFRs and at $\sim 2 \times 10^{-3} \mathrm{~s}^{-1}$ in the troposphere. Note that in this study we assume an average ambient $\mathrm{HO}_{2}$ concentration of $1.5 \times 10^{8}$ molecules $\mathrm{cm}^{-3}$ (Mao et al., 2009; Stone et al., 2012) and $\mathrm{RO}_{2}+\mathrm{HO}_{2}$ rate constant of $1.5 \times 10^{-11} \mathrm{~cm}^{3}$ molecule ${ }^{-1} \mathrm{~s}^{-1}$ (Orlando and Tyndall, 2012).

When daytime photochemistry is active, $\mathrm{NO}_{3}$ is negligible in the atmosphere. In OFR-iN $2 \mathrm{O}$ modes, $\mathrm{RO}_{2}+\mathrm{NO}_{3}$ is negligible unless at very low $\mathrm{H}_{2} \mathrm{O}$ and high $\mathrm{UV}$ intensity (abbreviated $\mathrm{UV}$ hereafter), which result in high $\mathrm{O}_{3}$ to oxidize $\mathrm{NO}_{2}$ to $\mathrm{NO}_{3}$ and keep $\mathrm{HO}_{2}$ minimized. However, very low $\mathrm{H}_{2} \mathrm{O}$ causes serious non-tropospheric organic photolysis (Peng et al., 2016) and thus these conditions are of no experimental interest.

In the atmosphere $\mathrm{RO}_{2}+\mathrm{O}_{3}$ is thought to play some role only at night (Orlando and Tyndall, 2012). Similar conditions may exist in some OFR254 cases if a very large amount of $\mathrm{O}_{3}$ is injected and $\mathrm{H}_{2} \mathrm{O}$ and $\mathrm{UV}$ are kept very low to limit $\mathrm{HO}_{x}$ production. These conditions are obviously not $\mathrm{OH}$ dominated and not further investigated in this study.

Of the $\mathrm{RO}_{2}$ fates considered in this study, $\mathrm{RO}_{2}+\mathrm{HO}_{2}$, $\mathrm{RO}_{2}+\mathrm{NO}$ and $\mathrm{RO}_{2}+\mathrm{RO}_{2}$ have long been known to play a role in the atmosphere (Orlando and Tyndall, 2012). Recommended general rate constants are available for $\mathrm{RO}_{2}+\mathrm{HO}_{2}$ and $\mathrm{RO}_{2}+\mathrm{NO}$ (Ziemann and Atkinson, 2012; Table 1), albeit with some small dependencies on the type of $\mathrm{RO}_{2}$ and a few deviations that are slightly larger but not important for the overall chemistry (e.g., $\mathrm{CH}_{3} \mathrm{O}_{2}$ and $\mathrm{C}_{2} \mathrm{H}_{5} \mathrm{O}_{2}$ for $\mathrm{RO}_{2}+\mathrm{HO}_{2}$ ). We use these recommended values for generic $\mathrm{RO}_{2}$ in this study. $\mathrm{RO}_{2}+\mathrm{NO}$ has two main product channels, i.e., $\mathrm{RO}+\mathrm{NO}_{2}$ and $\mathrm{RONO}_{2}$, whose branching ratios are $\mathrm{RO}_{2}$ structure dependent (Ziemann and Atkinson, 2012). We do not include these product channels in this study, since they have negligible impacts on the chemical scheme described here. This feature results from two facts: (i) we focus on generic $\mathrm{RO}_{2}$ and do not explicitly consider the chemistry of the products of different $\mathrm{RO}_{2}$ loss pathways; and (ii) the channel producing $\mathrm{RO}$ and $\mathrm{NO}_{2}$ contributes little to $\mathrm{NO}_{2}$ production (Peng et al., 2018). However, $\mathrm{RO}_{2}$ self- and cross-reaction rate constants are highly dependent on the specific $\mathrm{RO}_{2}$ types and can vary over a very large range $\left(10^{-17}-10^{-10} \mathrm{~cm}^{3}\right.$ molecule $\left.{ }^{-1} \mathrm{~s}^{-1}\right)$. Unsubstituted primary, secondary and tertiary $\mathrm{RO}_{2}$ radicals self-react at $\sim 10^{-13}, \sim 10^{-15}$ and $\sim 10^{-17} \mathrm{~cm}^{3}$ molecule ${ }^{-1} \mathrm{~s}^{-1}$, respectively (Ziemann and Atkinson, 2012). Rate constants of cross-reactions between these $\mathrm{RO}_{2}$ types also span this range (Orlando and Tyndall, 2012). Substituted $\mathrm{RO}_{2}$ types have higher self- and cross-reaction rate constants (Orlando 
Table 1. Rate constants (in $\mathrm{cm}^{3}$ molecule $\mathrm{s}^{-1} \mathrm{~s}^{-1}$ except for isomerization; in $\mathrm{s}^{-1}$ ), cross section (in $\mathrm{cm}^{2}$ ) and product(s) of $\mathrm{RO}_{2}$ loss pathways. Only organic species are listed for product(s).

\begin{tabular}{|c|c|c|}
\hline $\mathrm{RO}_{2}$ loss pathway & Rate constant or cross section & Product(s) \\
\hline $\mathrm{RO}_{2}+\mathrm{HO}_{2}$ & $1.5 \times 10^{-11^{\mathrm{a}}}$ & mainly $\mathrm{ROOH}$ for most $\mathrm{RO}_{2}{ }^{\mathrm{a}}$ \\
\hline $\mathrm{RO}_{2}+\mathrm{NO}$ & $9 \times 10^{-12^{\mathrm{a}}}$ & $\mathrm{RO}, \mathrm{RONO}_{2}{ }^{\mathrm{b}}$ \\
\hline \multirow{5}{*}{$\mathrm{RO}_{2}+\mathrm{RO}_{2}$} & Primary: $\sim 10^{-13^{\mathrm{a}}}$ & $\mathrm{ROH}+\mathrm{R}(=\mathrm{O}), \mathrm{RO}+\mathrm{RO}, \mathrm{ROOR}^{\mathrm{a}}$ \\
\hline & Secondary: $\sim 10^{-15^{\mathrm{a}}}$ & \\
\hline & Tertiary: $\sim 10^{-17^{\mathrm{a}}}$ & \\
\hline & $\begin{array}{l}\text { Substituted: can be up to } 2 \text { orders of } \\
\text { magnitude higher }\end{array}$ & \\
\hline & Acyl: $\sim 10^{-11^{\mathrm{b}}}$ & \\
\hline $\mathrm{RO}_{2}+\mathrm{NO}_{2}$ (in OFRs) & $7 \times 10^{-12^{c}}$ & $\mathrm{RO}_{2} \mathrm{NO}_{2}^{\mathrm{b}}$ \\
\hline $\mathrm{RO}_{2}+\mathrm{OH}$ & $1 \times 10^{-10^{\mathrm{d}}}$ & $\mathrm{ROOOH}\left(\right.$ for $\left.\geq \mathrm{C}_{4} \mathrm{RO}_{2}\right), \mathrm{RO}\left(\text { smaller } \mathrm{RO}_{2}\right)^{\mathrm{e}}$ \\
\hline $\mathrm{RO}_{2}$ isomerization & $\begin{array}{l}\text { Autoxidation: } \sim 10^{-3}-10^{2^{\mathrm{f}}} \\
\text { Other: up to } 10^{6^{\mathrm{g}}}\end{array}$ & generally another $\mathrm{RO}_{2}$ \\
\hline $\mathrm{RO}_{2}$ photolysis & $\begin{array}{l}\sim 10^{-18} \text { at } 254 \mathrm{~nm}^{\mathrm{h}} \\
\sim 10^{-21}-10^{-19} \text { in UVA and } \mathrm{UVB}^{\mathrm{h}}\end{array}$ & mainly $\mathrm{R}$, other photochemical products possible $\mathrm{e}^{\mathrm{i}}$ \\
\hline $\mathrm{RO}_{2}+\mathrm{NO}_{3}$ & $\sim 1-3 \times 10^{-12^{\mathrm{b}}}$ & $\mathrm{RO}^{\mathrm{b}}$ \\
\hline $\mathrm{RO}_{2}+\mathrm{O}_{3}$ & $\sim 10^{-17^{b}}$ & $\mathrm{RO}^{\mathrm{b}}$ \\
\hline
\end{tabular}

${ }^{\mathrm{a}}$ Ziemann and Atkinson (2012). ${ }^{\mathrm{b}}$ Orlando and Tyndall (2012); ${ }^{\mathrm{c}}$ typical value within the reported range in Orlando and Tyndall (2012); thermal decomposition rate constants of nitrates of acyl and non-acyl $\mathrm{RO}_{2}$ are assumed to be 0.0004 and $3 \mathrm{~s}^{-1}$, respectively, which are also typical values within the reported ranges in Orlando and Tyndall (2012). ${ }^{\mathrm{d}}$ Value used in the present work based on Bossolasco et al. (2014); Assaf et al. (2016, 2017a); Müller et al. (2016); Yan et al. (2016). ${ }^{\mathrm{e}}$ Müller et al. (2016); Yan et al. (2016); Assaf et al. (2017b, 2018). ${ }^{\mathrm{f}}$ Crounse et al. (2013). ${ }^{\mathrm{g}}$ Knap and Jørgensen (2017).

${ }^{\mathrm{h}}$ Burkholder et al. (2015). ${ }^{\mathrm{i}}$ Klems et al. (2015).

and Tyndall, 2012). $\mathrm{RO}_{2}+\mathrm{RO}_{2}$ of highly substituted primary $\mathrm{RO}_{2}$ can be as high as $\sim 10^{-11} \mathrm{~cm}^{3}$ molecule ${ }^{-1} \mathrm{~s}^{-1}$ (Orlando and Tyndall, 2012). Very recently, a few highly oxidized 1,3,5-trimethylbenzene-derived $\mathrm{RO}_{2} \mathrm{~s}$ were reported to self- and cross-react at $\sim 10^{-10} \mathrm{~cm}^{3}$ molecule ${ }^{-1} \mathrm{~s}^{-1}$ (Berndt et al., 2018). In the present work, we make a simplification to adapt to the generic $\mathrm{RO}_{2}$ treatment by assuming a single selfand cross-reaction rate constant for generic $\mathrm{RO}_{2}$ in each case. Three levels of $\mathrm{RO}_{2}+\mathrm{RO}_{2}$ rate constants, i.e., $1 \times 10^{-13}, 1 \times$ $10^{-11}$ and $1 \times 10^{-10} \mathrm{~cm}^{3}$ molecule ${ }^{-1} \mathrm{~s}^{-1}$, are studied in this paper. The first level is referred to as "medium $\mathrm{RO}_{2}+\mathrm{RO}_{2}$ " as many other $\mathrm{RO}_{2}$ types can have self- and cross-reaction rate constants as low as $10^{-17} \mathrm{~cm}^{3}$ molecule ${ }^{-1} \mathrm{~s}^{-1}$; the second level is defined as "fast $\mathrm{RO}_{2}+\mathrm{RO}_{2}$ "; and the last level is called "very fast $\mathrm{RO}_{2}+\mathrm{RO}_{2}$ ". No $\mathrm{RO}_{2}+\mathrm{RO}_{2}$ rate constant lower than the medium level is investigated in the current work, although there are still a large variety of $\mathrm{RO}_{2}$ types whose self- and cross-reactions are at lower rate constants, since at the medium level, $\mathrm{RO}_{2}+\mathrm{RO}_{2}$ is already negligible in all the environments studied in this work, i.e., OFRs, chambers and the atmosphere (see Sect. 3.1.1). Since there are only a few very specific examples for very fast $\mathrm{RO}_{2}+\mathrm{RO}_{2}$ reported to date, we will not systematically explore this category but compare very fast $\mathrm{RO}_{2}+\mathrm{RO}_{2}$ as a sensitivity case with the other two types of $\mathrm{RO}_{2}+\mathrm{RO}_{2}$ reactions.

Acyl $\mathrm{RO}_{2}$ is considered as a separate $\mathrm{RO}_{2}$ type (neither medium nor fast $\mathrm{RO}_{2}+\mathrm{RO}_{2}$ ) in this study since its reaction with $\mathrm{NO}_{2}$ can be a major sink of $\mathrm{RO}_{2}$ in OFR
(Peng and Jimenez, 2017). Thermal decomposition lifetimes of the product of $\mathrm{RO}_{2}+\mathrm{NO}_{2}$, i.e., acylperoxy nitrates, can be hours at laboratory temperatures (Orlando and Tyndall, 2012; also taken into account in the current work; see Table 1), while OFR residence times are typically minutes. Besides, acyl $\mathrm{RO}_{2}$ reacts with many $\mathrm{RO}_{2}$ types at $\sim 10^{-11} \mathrm{~cm}^{3}$ molecule ${ }^{-1} \mathrm{~s}^{-1}$ (Orlando and Tyndall, 2012), similar to that of fast $\mathrm{RO}_{2}+\mathrm{RO}_{2}$. We thus assume the acyl $\mathrm{RO}_{2}$ self- and cross-reaction rate constant to also be $1 \times 10^{-11} \mathrm{~cm}^{3}$ molecule ${ }^{-1} \mathrm{~s}^{-1}$ to facilitate comparison with fast $\mathrm{RO}_{2}+\mathrm{RO}_{2}$ results.

In OFRs operated at room temperature, acylperoxy nitrates barely decompose, as their thermal decomposition lifetime is typically $\sim 1 \mathrm{~h}$ (Orlando and Tyndall, 2012), while OFR residence time is usually a few minutes. In contrast, peroxy nitrates of non-acyl $\mathrm{RO}_{2}$ do decompose on a timescale of $0.1 \mathrm{~s}$ (Orlando and Tyndall, 2012; Table 1). As a consequence, the production and decomposition of peroxy nitrates of nonacyl $\mathrm{RO}_{2}$ reach a steady state in OFRs, which can be greatly shifted toward the peroxy nitrate side in cases with very high $\mathrm{NO}_{2}$ (Peng and Jimenez, 2017; Peng et al., 2018).

$\mathrm{RO}_{2}+\mathrm{OH}$ (Fittschen et al., 2014) and $\mathrm{RO}_{2}$ isomerization (Crounse et al., 2013) have recently been identified as possible significant $\mathrm{RO}_{2}$ fates in the atmosphere. Reactions of the former type, according to several recent experimental and theoretical studies (Bossolasco et al., 2014; Assaf et al., 2016, 2017a, b; Müller et al., 2016; Yan et al., 2016), have similar rate constants ( $1 \times$ 
$10^{-10} \mathrm{~cm}^{3}$ molecule ${ }^{-1} \mathrm{~s}^{-1}$ ) regardless of $\mathrm{RO}_{2}$ type. Therefore, the reaction rate constant of generic $\mathrm{RO}_{2}$ with $\mathrm{OH}$ is assigned as $1 \times 10^{-10} \mathrm{~cm}^{3}$ molecule ${ }^{-1} \mathrm{~s}^{-1} . \mathrm{RO}_{2}$ isomerization reactivity is highly structure dependent (Crounse et al., 2013; Praske et al., 2018) and rate constant measurements are still scarce, preventing us from assigning a generic $\mathrm{RO}_{2}$ isomerization rate constant. However, for generic $\mathrm{RO}_{2}$, isomerization is generally not a sink but a conversion between two $\mathrm{RO}_{2}$ radicals (both encompassed by the generic one in this study), as $\mathrm{RO}_{2}$ isomerization usually generates an oxygenated hydrocarbyl radical, which rapidly recombines with $\mathrm{O}_{2}$ and forms another $\mathrm{RO}_{2}$. Therefore, $\mathrm{RO}_{2}$ isomerization is not explicitly taken into account in the modeling, but is considered in the $\mathrm{RO}_{2}$ fate analysis.

In summary, six pathways are included in the $\mathrm{RO}_{2}$ fate analysis of this study. The need to explore these six pathways for a high number of OFR, chamber and atmospheric conditions makes the presentation of results challenging. For clarity, we present the results in two steps. In the first step, only well-known $\mathrm{RO}_{2}$ fates (reaction with $\mathrm{NO}_{2}, \mathrm{HO}_{2}, \mathrm{NO}$ and $\mathrm{RO}_{2}$ ) will be included in the model. In the second step, the results of the first step will be used to guide the modeling and analysis of a more comprehensive set of significant $\mathrm{RO}_{2}$ fates.

\subsection{Model description}

The model used in the present work is a standard chemical kinetic box model implemented in the KinSim 3.4 solver in Igor Pro 7 (WaveMetrics, Lake Oswego, Oregon, USA) and has been described in detail elsewhere (Peng et al., 2015, 2018). Plug flow in the reactor with a residence time of $180 \mathrm{~s}$ is assumed, since the effects of non-plug flow are major only in a narrow range of conditions of little experimental interest, and the implementation of laminar flow or measured residence time distribution substantially increases computational cost (Peng et al., 2015; Peng and Jimenez, 2017). The reactions of $\mathrm{RO}_{2}$ discussed in Sect. 2.2 are added to the chemical mechanism. A generic slow-reacting VOC (with the same $\mathrm{OH}$ rate constant as $\mathrm{SO}_{2}$ ) is used as the external $\mathrm{OH}$ reactant. Its initial concentration is determined by the initial $\mathrm{OHR}_{\mathrm{ext}}$ in each model case. Then as this proxy external $\mathrm{OH}$ reactant slowly reacts, $\mathrm{OHR}_{\text {ext }}$ slowly decays. This slow change in $\mathrm{OHR}_{\text {ext }}$ represents not only the decay of the initial reactant but also the generation and consumption of later-generation products that continue to react with $\mathrm{OH}$. The reason for this approximation has been discussed in detail in previous OFR modeling papers (Peng and Jimenez, 2017; Peng et al., 2018). We exclude $\mathrm{NO}_{y}$ species, which are explicitly modeled, from the calculation of $\mathrm{OHR}_{\text {ext }}$; thus, $\mathrm{OHR}_{\mathrm{ext}}$ only includes non- $\mathrm{NO}_{y} \mathrm{OHR}_{\text {ext }}$ hereafter. As $\mathrm{OHR}_{\text {ext }}$ is dominated by $\mathrm{OHR}_{\mathrm{VOC}}$ in most OFR experiments, we use $\mathrm{OHR}_{\text {ext }}$ to denote OHR $_{V O C}$ in OFRs (while for ambient and chamber cases $\mathrm{OHR}_{\text {VOC }}$ is still used to exclude the contribution of $\mathrm{CO}$, etc.). The outputs of our model (e.g., species concentrations and exposures) were estimated to be accurate to within a factor of 2-3 when compared with field OFR experiments; better agreement can generally be obtained for laboratory OFR experiments (Li et al., 2015; Peng et al., 2015).

Another key parameter in the model is the $\mathrm{HO}_{x}$ recycling ratio $(\beta)$, defined in this study as the number of $\mathrm{HO}_{2}$ molecule(s) produced per $\mathrm{OH}$ molecule destroyed by external OH reactants (Peng et al., 2015). This ratio depends on the products of $\mathrm{RO}_{2}$ loss pathways. The main product of $\mathrm{RO}_{2}+\mathrm{HO}_{2}$ is usually $\mathrm{ROOH}$ (Table 1 ), yielding no recycled $\mathrm{HO}_{2}$, while the main products of $\mathrm{RO}_{2}+\mathrm{NO}$ are $\mathrm{RO}$ and $\mathrm{NO}_{2}$, the former of which can often undergo extremely fast $\mathrm{H}$ abstraction by $\mathrm{O}_{2}$ to form a carbonyl and $\mathrm{HO}_{2}$. We used the fully chemically explicit (automated chemical mechanism generation based on available knowledge) box model GECKO-A (Aumont et al., 2005) to simulate OH oxidation of several simple VOCs (e.g., propane and decane) under various OFR conditions with zero NO. We consistently find that $\beta \sim 0.3$. At the other extreme, when $\mathrm{RO}_{2}$ is solely consumed by $\mathrm{RO}_{2}+\mathrm{NO}$, the product $\mathrm{RO}$ yields $\mathrm{HO}_{2}$ at a branching ratio close to $1, \beta \sim 1$. For intermediate cases, we assume that $\beta$ may be interpolated as a linear function of $\mathrm{r}\left(\mathrm{RO}_{2}+\mathrm{NO}\right) /\left[\mathrm{r}\left(\mathrm{RO}_{2}+\mathrm{NO}\right)+\mathrm{r}\left(\mathrm{RO}_{2}+\mathrm{HO}_{2}\right)\right]$, where $\mathrm{r}\left(\mathrm{RO}_{2}+\mathrm{NO}\right)$ and $\mathrm{r}\left(\mathrm{RO}_{2}+\mathrm{HO}_{2}\right)$ are the local reactive fluxes of $\mathrm{RO}_{2}+\mathrm{NO}$ and $\mathrm{RO}_{2}+\mathrm{HO}_{2}$.

In the present work, we model OFR185, OFR254-70 and OFR254-7 (including their $\mathrm{iN}_{2} \mathrm{O}$ variants). We specify the same temperature and atmospheric pressure (295 K and 835 mbar, typical values in Boulder, Colorado, USA) as our previous OFR modeling studies (Li et al., 2015; Peng et al., 2015, 2016, 2018; Peng and Jimenez, 2017). The explored physical condition space follows that of our previous OFR$\mathrm{iN}_{2} \mathrm{O}$ modeling work (Peng et al., 2018). The only differences are that in this study we also include cases without any $\mathrm{N}_{2} \mathrm{O}$ injected (OFR185 and OFR254 only) and exclude $\mathrm{OHR}_{\mathrm{ext}}=0$ conditions, which produce no $\mathrm{RO}_{2}$. In detail, the explored physical condition space covers the following: $\mathrm{H}_{2} \mathrm{O}$ of $0.07 \%-2.3 \%$ (relative humidity of $2 \%-71 \%$ at $295 \mathrm{~K}$ ); UV photon flux at $185 \mathrm{~nm}$ (abbreviated F185) of $1.0 \times 10^{11}$ $1.0 \times 10^{14}$ photons $\mathrm{cm}^{-2} \mathrm{~s}^{-1}$ (corresponding photon flux at $254 \mathrm{~nm}$ (F254) of $4.2 \times 10^{13}-8.5 \times 10^{15}$ photons $\mathrm{cm}^{-2} \mathrm{~s}^{-1}$ ); $\mathrm{OHR}_{\text {ext }}$ of $1-1000 \mathrm{~s}^{-1}$; and $\mathrm{N}_{2} \mathrm{O}$ mixing ratio (abbreviated $\mathrm{N}_{2} \mathrm{O}$ hereafter) of 0 and $0.02 \%-20 \%$. All model cases are logarithmically evenly distributed except for $\mathrm{N}_{2} \mathrm{O}=0$ and F254. The latter is calculated based on the F185-F254 relationship for the lamps simulated here (Li et al., 2015).

For the classification of conditions, the same criteria as in the OFR-iN ${ }_{2} \mathrm{O}$ modeling study (Peng et al., 2018) are adopted. In detail, high- and low-NO conditions are classified by $\mathrm{r}\left(\mathrm{RO}_{2}+\mathrm{NO}\right) / \mathrm{r}\left(\mathrm{RO}_{2}+\mathrm{HO}_{2}\right)$. In the current work, these reactive fluxes are explicitly tracked in the modeling instead of approximated as in previous studies (Peng and Jimenez, 2017; Peng et al., 2018). The terms "good," "risky" and "bad" are used to describe OFR operating conditions in terms of non-tropospheric organic photolysis and are defined 
based on the ratios of F185 and F254 exposure (F185 exp and F254 $4_{\exp }$, i.e., integrated photon fluxes over residence time) to $\mathrm{OH}$ exposure $\left(\mathrm{OH}_{\text {exp }}\right)$, as presented previously (Peng and Jimenez, 2017; Peng et al., 2018). Briefly, under a given condition non-tropospheric photolysis is of different relative importance in the fate of each specific organic species: under good conditions, photolysis at 185 and/or $254 \mathrm{~nm}$ is unimportant for almost all VOCs; under bad conditions, nontropospheric photolysis is problematic for most VOC precursors, since significant photolysis of their oxidation intermediates at $185 \mathrm{and} /$ or $254 \mathrm{~nm}$ is almost inevitable; and risky conditions can be problematic for some but not all VOCs. Note that good, risky or bad conditions refer only to non-tropospheric organic photolysis and not to whether $\mathrm{RO}_{2}$ chemistry is atmospherically relevant. Table $\mathrm{S} 1$ summarizes our condition classification criteria.

\section{Results and discussion}

In this section, the results are presented in two parts, i.e., first for the simulations with well-known pathways only and secondly with all significant pathways, as proposed in Sect. 2.2. Then based on the results and their comparison with the atmosphere and chamber experiments, we propose guidelines for OFR operation to ensure atmospherically relevant $\mathrm{RO}_{2}$ chemistry, as well as other chemistries already discussed in the previous studies (Peng et al., 2016, 2018), in OFRs.

\subsection{Simulations with well-known pathways $\left(\mathrm{RO}_{2}+\mathrm{HO}_{2}, \mathrm{RO}_{2}+\mathrm{RO}_{2}, \mathrm{RO}_{2}+\mathrm{NO}\right.$ and $\mathrm{RO}_{2}+\mathrm{NO}_{2}$ )}

Due to the significantly different reactivities of non-acyl and acyl $\mathrm{RO}_{2}$, the results of these two types of $\mathrm{RO}_{2}$ are shown separately.

\subsubsection{Non-acyl $\mathrm{RO}_{2}$}

In this case non-acyl $\mathrm{RO}_{2}$ radicals have only three fates, i.e., $\mathrm{RO}_{2}+\mathrm{HO}_{2}, \mathrm{RO}_{2}+\mathrm{NO}$ and $\mathrm{RO}_{2}+\mathrm{RO}_{2}$. The relative importance of these three fates can be shown in a triangle plot (Fig. 1). The figure includes data points of OFR185 (including OFR185-iN $2 \mathrm{O}$ ) and OFR254-70 (including OFR254-70$\mathrm{iN}_{2} \mathrm{O}$ ), as well as several typical ambient and chamber studies, including two pristine remote area cases $\left(\mathrm{P}_{1}\right.$ and $\left.\mathrm{P}_{2}\right)$ from the ATom-1 study (Wofsy et al., 2018), two forested area cases $\left(\mathrm{F}_{1}\right.$ and $\left.\mathrm{F}_{2}\right)$ from the BEACHON-RoMBAS and GoAmazon campaigns, respectively (Ortega et al., 2014; Martin et al., 2016, 2017), an urban area case (U) from the CalNex-LA campaign (Ryerson et al., 2013), and five typical chamber experiment cases $\left(\mathrm{C}_{1}-\mathrm{C}_{5}\right)$ from the FIXCIT study (Nguyen et al., 2014). These typical cases shown in Fig. 1 bring to light several interesting points.

- In all ambient and chamber cases, medium and slower $\mathrm{RO}_{2}+\mathrm{RO}_{2}$ contribute negligibly to the $\mathrm{RO}_{2}$ fate. This confirms a common impression that self- and crossreactions of many $\mathrm{RO}_{2}$ radicals do not significantly affect $\mathrm{RO}_{2}$ fates.

- However, if $\mathrm{RO}_{2}$ self- and cross-reacts rapidly, $\mathrm{RO}_{2}+$ $\mathrm{RO}_{2}$ can be the most important loss pathway among $\mathrm{RO}_{2}+\mathrm{RO}_{2}, \mathrm{RO}_{2}+\mathrm{HO}_{2}$ and $\mathrm{RO}_{2}+\mathrm{NO}$ even in pristine regions with higher VOC (e.g., $\mathrm{P}_{1}$ in Fig. 1) compared to an average pristine region case $\left(\mathrm{P}_{2}\right)$. Note that the $\mathrm{P}_{1}$ case is still very clean compared to typical forested and urban areas (Table 2).

- Forested areas located in the same region as pollution sources are not as "low NO" as one may expect (points $\mathrm{F}_{1}$ and $\mathrm{F}_{2}$ in Fig. 1). $\mathrm{RO}_{2}+\mathrm{NO}$ contributes $\sim 20 \%-$ $50 \%$ to $\mathrm{RO}_{2}$ loss, as $\mathrm{NO}$ and $\mathrm{HO}_{2}$ concentrations are of the same order of magnitude in these cases.

- $\mathrm{RO}_{2}+\mathrm{NO}$ dominates over $\mathrm{RO}_{2}+\mathrm{RO}_{2}$ and $\mathrm{RO}_{2}+\mathrm{HO}_{2}$ in almost all urban areas. Even in relatively clean urban areas such as Los Angeles during CalNex-LA in 2010 (point $\mathrm{U}$ in Fig. 1), average NO is $\sim 1 \mathrm{ppb}$, still sufficiently high to ensure the dominance of $\mathrm{RO}_{2}+\mathrm{NO}$ among the three pathways.

- Various chamber cases in the FIXCIT campaign (low to high $\mathrm{OHR}_{\text {ext }}$; low to high NO; points $C_{x}$ in Fig. 1) are able to represent specific $\mathrm{RO}_{2}$ fates that appear in different regions in the atmosphere.

On these plots, points for bad conditions (in terms of nontropospheric photolysis) are not shown because of the lack of experimental interest. The triangle plots for OFR254-7 (including OFR254-7-iN $2 \mathrm{O}$ ) in the same form (Supplement Fig. S1a, b) show no qualitative differences from the results of OFR254-70, implying that initial $\mathrm{O}_{3}$ in OFR254 modes has only minor impacts on $\mathrm{RO}_{2}$ fate. We see this result not only for well-known non-acyl $\mathrm{RO}_{2}$ fate, but also for the aspects discussed in the following sections. The similarity between OFR254 modes can be explained by the minor effects of a lower $\mathrm{O}_{3}$ on $\mathrm{HO}_{x}$ at relatively low $\mathrm{OHR}_{\text {ext }}$ (Peng et al., 2015). Cases at higher $\mathrm{OHR}_{\mathrm{ext}}$ often have stronger nontropospheric photolysis (Peng et al., 2016) and hence are more likely to be under bad conditions and are not shown in Figs. 1 and S1a, b. For simplicity, this similarity is not discussed further.

An important feature confirmed in Fig. 1 is that $\mathrm{OFR}-\mathrm{iN}_{2} \mathrm{O}$ modes effectively realize conditions of experimental interest with variable relative importance of $\mathrm{RO}_{2}+\mathrm{NO}$ in $\mathrm{RO}_{2}$ fate (Lambe et al., 2017; Peng et al., 2018). Tuning initially injected $\mathrm{N}_{2} \mathrm{O}$ can achieve this goal (Fig. 2). While it is possible to reduce $\mathrm{RO}_{2}+\mathrm{HO}_{2}$ in OFR185-iN $\mathrm{N}_{2} \mathrm{O}$ to negligible compared to $\mathrm{RO}_{2}+\mathrm{NO}$ by increasing $\mathrm{N}_{2} \mathrm{O}$, this is not possible in OFR254-70- $\mathrm{iN}_{2} \mathrm{O}$ due to fast $\mathrm{NO}$ oxidation by the large amounts of $\mathrm{O}_{3}$ added in the reactor. Nevertheless, OFR254$70-\mathrm{iN}_{2} \mathrm{O}$ can still make $\mathrm{RO}_{2}+\mathrm{NO}$ dominate over $\mathrm{RO}_{2}+\mathrm{HO}_{2}$ 


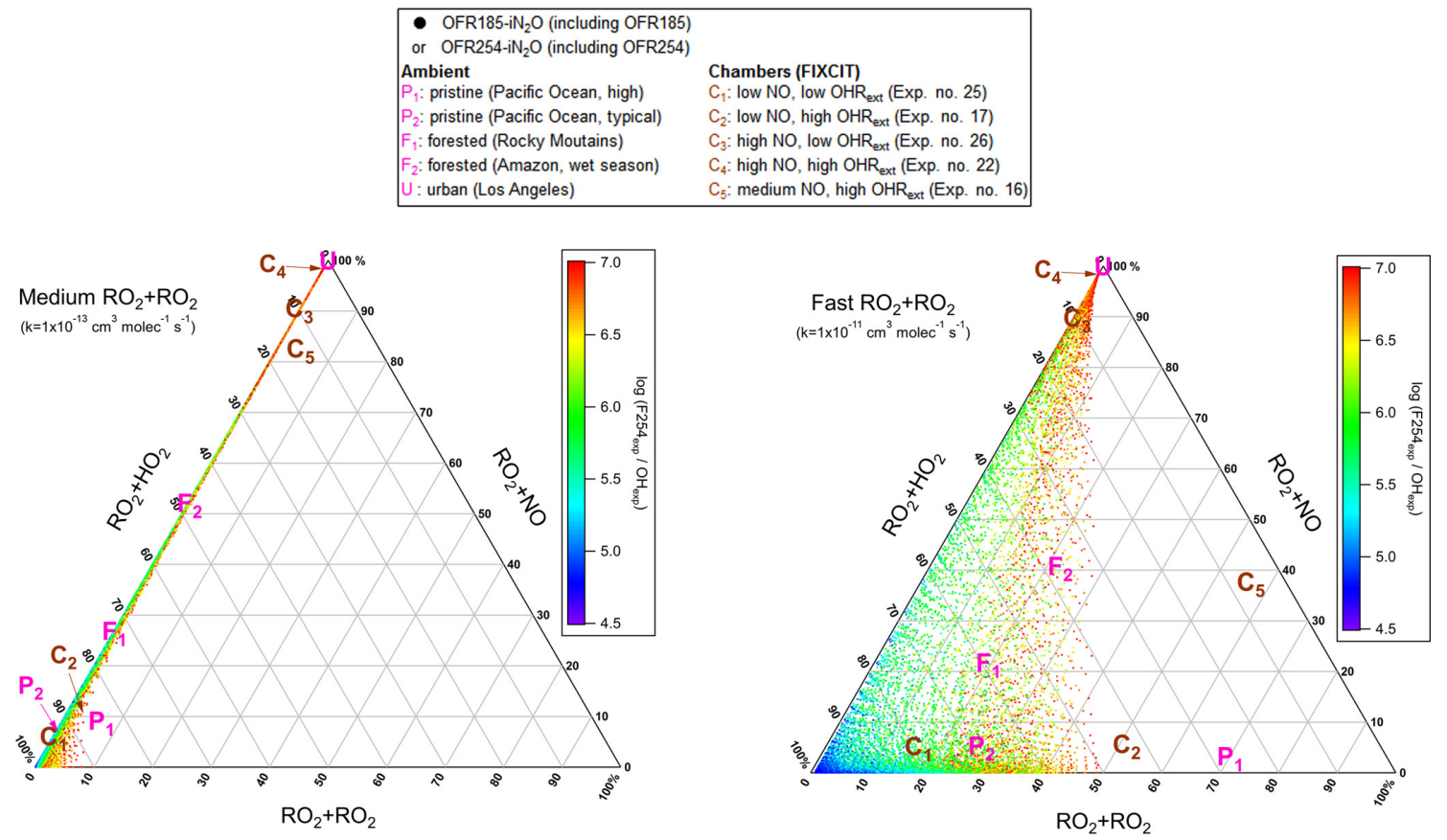

(a) OFR185

(b) OFR185

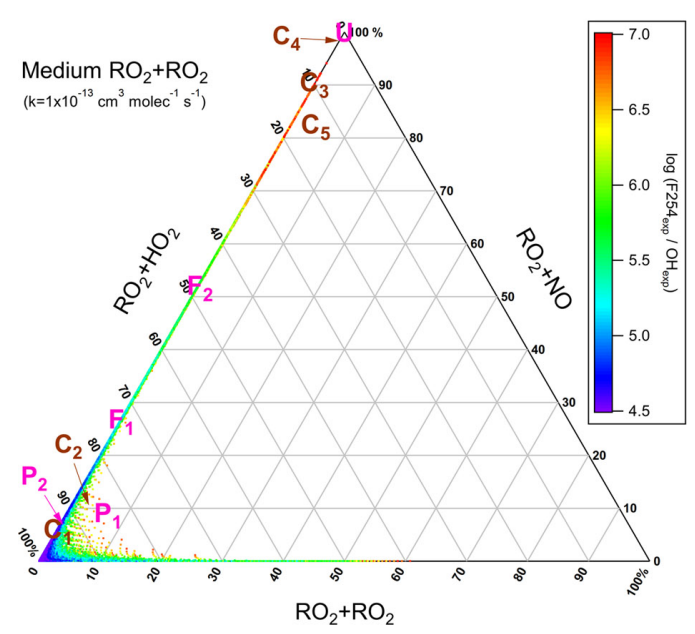

(c) OFR254-70

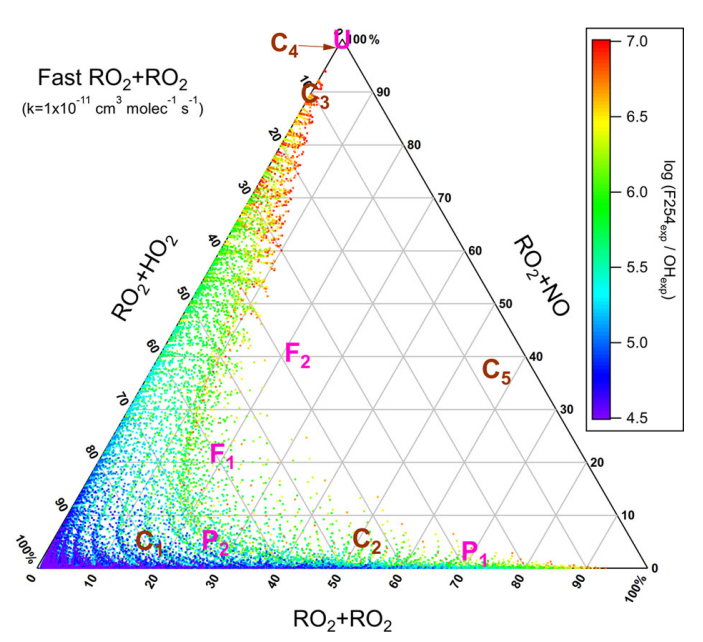

(d) OFR254-70

Figure 1. Triangle plots of $\mathrm{RO}_{2}$ fate by $\mathrm{RO}_{2}+\mathrm{HO}_{2}, \mathrm{RO}_{2}+\mathrm{RO}_{2}$ and $\mathrm{RO}_{2}+\mathrm{NO}$ (without $\mathrm{RO}_{2}+\mathrm{OH}$ and $\mathrm{RO}_{2}$ isomerization considered in the model) for $\mathrm{RO}_{2}$ with the medium self- and cross-reaction rate constant $\left(1 \times 10^{-13} \mathrm{~cm}^{-3}\right.$ molecule $\left.{ }^{-1} \mathrm{~s}^{-1}\right)$ in (a) OFR185 (including OFR185-iN $2 \mathrm{O}$ ) and (c) OFR254-70 (including OFR254-70-iN $2 \mathrm{O})$ and for RO2 with the fast self- and cross-reaction rate constant $(1 \times$ $10^{-11} \mathrm{~cm}^{-3}$ molecule $\mathrm{s}^{-1}$ ) in (b) OFR185 (including OFR185-iN $2 \mathrm{O}$ ) and (d) OFR254-70 (including OFR254-70-iN $2 \mathrm{O}$ ). Inclined tick values on an axis indicate the grid lines that should be followed (in parallel to the inclination) to read the corresponding values on this axis. The OFR data points are colored by the logarithm of the exposure ratio between $254 \mathrm{~nm}$ photon flux and OH, a measure of badness of OFR conditions in terms of $254 \mathrm{~nm}$ organic photolysis. Several typical ambient and chamber cases (see Table 2 for details on these cases) are also shown for comparison.

in $\mathrm{RO}_{2}$ fate. $\mathrm{OFR}$ and chamber cases span a range of $\sim 0 \%-$ $\sim 100 \%$ in relative importance of $\mathrm{RO}_{2}+\mathrm{NO}$ in $\mathrm{RO}_{2}$ fate (Fig. 2), suggesting that both chambers and OFRs are able to ensure the atmospheric relevance of $\mathrm{RO}_{2}+\mathrm{NO}$ in $\mathrm{RO}_{2}$ fate.
Another important feature that can be easily seen in Fig. 1 is that medium-rate $\mathrm{RO}_{2}+\mathrm{RO}_{2}$ (and hence also $\mathrm{RO}_{2}+\mathrm{RO}_{2}$ slower than $10^{-13} \mathrm{~cm}^{3}$ molecule ${ }^{-1} \mathrm{~s}^{-1}$ ) is of negligible importance in the fate of $\mathrm{RO}_{2}$ (Fig. 1a, c) in OFR185 (including OFR185-iN $2 \mathrm{O}$ ), OFR254-70 (under most conditions, in- 

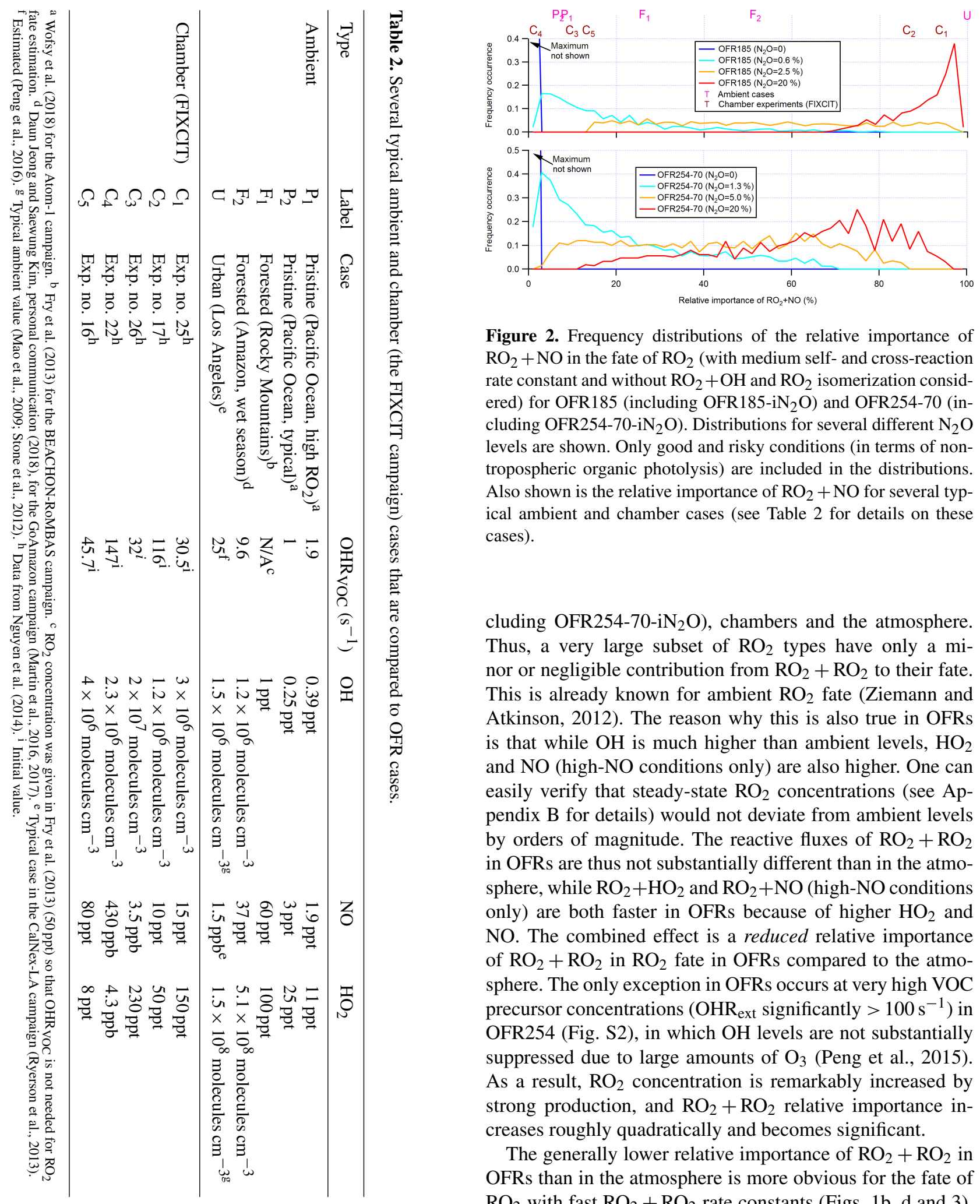

Figure 2. Frequency distributions of the relative importance of $\mathrm{RO}_{2}+\mathrm{NO}$ in the fate of $\mathrm{RO}_{2}$ (with medium self- and cross-reaction rate constant and without $\mathrm{RO}_{2}+\mathrm{OH}$ and $\mathrm{RO}_{2}$ isomerization considered) for OFR185 (including OFR185-iN $2 \mathrm{O}$ ) and OFR254-70 (including OFR254-70-iN $\mathrm{N}_{2} \mathrm{O}$ ). Distributions for several different $\mathrm{N}_{2} \mathrm{O}$ levels are shown. Only good and risky conditions (in terms of nontropospheric organic photolysis) are included in the distributions. Also shown is the relative importance of $\mathrm{RO}_{2}+\mathrm{NO}$ for several typical ambient and chamber cases (see Table 2 for details on these cases).

cluding OFR254-70-i $\mathrm{N}_{2} \mathrm{O}$ ), chambers and the atmosphere. Thus, a very large subset of $\mathrm{RO}_{2}$ types have only a minor or negligible contribution from $\mathrm{RO}_{2}+\mathrm{RO}_{2}$ to their fate. This is already known for ambient $\mathrm{RO}_{2}$ fate (Ziemann and Atkinson, 2012). The reason why this is also true in OFRs is that while $\mathrm{OH}$ is much higher than ambient levels, $\mathrm{HO}_{2}$ and NO (high-NO conditions only) are also higher. One can easily verify that steady-state $\mathrm{RO}_{2}$ concentrations (see Appendix $\mathrm{B}$ for details) would not deviate from ambient levels by orders of magnitude. The reactive fluxes of $\mathrm{RO}_{2}+\mathrm{RO}_{2}$ in OFRs are thus not substantially different than in the atmosphere, while $\mathrm{RO}_{2}+\mathrm{HO}_{2}$ and $\mathrm{RO}_{2}+\mathrm{NO}$ (high- $\mathrm{NO}$ conditions only) are both faster in OFRs because of higher $\mathrm{HO}_{2}$ and NO. The combined effect is a reduced relative importance of $\mathrm{RO}_{2}+\mathrm{RO}_{2}$ in $\mathrm{RO}_{2}$ fate in OFRs compared to the atmosphere. The only exception in OFRs occurs at very high VOC precursor concentrations $\left(\mathrm{OHR}_{\mathrm{ext}}\right.$ significantly $\left.>100 \mathrm{~s}^{-1}\right)$ in OFR254 (Fig. S2), in which OH levels are not substantially suppressed due to large amounts of $\mathrm{O}_{3}$ (Peng et al., 2015). As a result, $\mathrm{RO}_{2}$ concentration is remarkably increased by strong production, and $\mathrm{RO}_{2}+\mathrm{RO}_{2}$ relative importance increases roughly quadratically and becomes significant.

The generally lower relative importance of $\mathrm{RO}_{2}+\mathrm{RO}_{2}$ in OFRs than in the atmosphere is more obvious for the fate of $\mathrm{RO}_{2}$ with fast $\mathrm{RO}_{2}+\mathrm{RO}_{2}$ rate constants (Figs. $1 \mathrm{~b}, \mathrm{~d}$ and 3 ). Although OFRs can reasonably reproduce $\mathrm{RO}_{2}$ fates in typical low- and moderate-OHR ext ambient environments (e.g., typical pristine and forested areas; Figs. 1b, d and 3) and lowOHR $_{\text {ext }}$ chambers, OFR185 cannot achieve a relative importance of $\mathrm{RO}_{2}+\mathrm{RO}_{2}$ significantly larger than $50 \%$, such as 
found in remote environments with higher VOC (e.g., $\mathrm{P}_{1}$ in Fig. 1) and high-OHR ext chamber experiments (e.g., $\mathrm{C}_{2}$ and $\mathrm{C}_{5}$ in Fig. 1; the distribution for $\mathrm{C}_{2}$ is also shown in Fig. 3). In OFR254-70, a relative importance of $\mathrm{RO}_{2}+\mathrm{RO}_{2}$ as high as $\sim 90 \%$ may be attained (Fig. S3). However, this requires very high $\mathrm{OHR}_{\mathrm{ext}}$, which leads to medium (and slower) $\mathrm{RO}_{2}+\mathrm{RO}_{2}$ showing higher-than-ambient relative importance. In reality, fast $\mathrm{RO}_{2}+\mathrm{RO}_{2}$ reactions all involve substituted $\mathrm{RO}_{2}$, which almost certainly arises from and coexists with unsubstituted $\mathrm{RO}_{2}$ (with slower self- and crossreactions). Therefore, very high $\mathrm{OHR}_{\text {ext }}$ in OFR254 is not really suitable for attaining dominant $\mathrm{RO}_{2}+\mathrm{RO}_{2}$ conditions. In OFR185, a higher $\mathrm{OHR}_{\text {ext }}$ generally also results in a higher $\mathrm{RO}_{2}+\mathrm{RO}_{2}$ relative importance because of higher $\mathrm{RO}_{2}$ production (Fig. S3). Nevertheless, higher OHR ext is more likely to lead to risky or bad conditions (Fig. 3; Peng et al., 2016). It should be noted that although it is difficult to reliably achieve $\mathrm{RO}_{2}+\mathrm{RO}_{2}$ with a relative importance larger than $50 \%$ in $\mathrm{RO}_{2}$ fate in OFRs, the distributions of $\mathrm{RO}_{2}+\mathrm{RO}_{2}$ relative importance in OFRs seem to be within a factor of 2 of those of field and aircraft campaigns (Fig. 3).

In the case of very fast $\mathrm{RO}_{2}+\mathrm{RO}_{2}$, all features for fast $\mathrm{RO}_{2}+\mathrm{RO}_{2}$ discussed above are still present (Fig. S1c, d). The only major difference between the results for fast $\mathrm{RO}_{2}+\mathrm{RO}_{2}$ and very fast $\mathrm{RO}_{2}+\mathrm{RO}_{2}$ is the significantly higher relative importance of $\mathrm{RO}_{2}+\mathrm{RO}_{2}$ in $\mathrm{RO}_{2}$ fate in the latter case, which is expected. In summary, fast $\mathrm{RO}_{2}+\mathrm{RO}_{2}$ is not perfectly reproduced in OFRs in terms of relative importance in $\mathrm{RO}_{2}$ fate, but it is significant when this pathway is also important in the atmosphere.

The $\mathrm{HO}_{x}$ recycling ratio $\beta$ (see Sect. 2.3) is one of the key factors determining $\mathrm{HO}_{2}$ in the OFR model, yet it is not well constrained. Although we make reasonable assumptions for it in the model input (see Sect. 2.3 for details), a sensitivity study to explore its effects is also performed here. For $\mathrm{RO}_{2}$ with the fast self- and cross-reaction rate constant, we perform simulations with the $\mathrm{HO}_{x}$ recycling ratios fixed to a number of values from 0 (radical termination) to 2 (radical proliferation) in lieu of those calculated under the assumptions described in Sect. 2.3. As expected, the contribution of $\mathrm{RO}_{2}+\mathrm{RO}_{2}$ to $\mathrm{RO}_{2}$ fate increases monotonically between $\beta=2$ and $\beta=0$ (Fig. S4) as the recycling of the competing reactant $\mathrm{HO}_{2}$ decreases. Nevertheless, the change in the average $\mathrm{RO}_{2}+\mathrm{RO}_{2}$ relative importance from $\beta=0$ to $\beta=2$ is generally within a factor of 2 . Thus, it still holds that the $\mathrm{RO}_{2}+\mathrm{RO}_{2}$ relative importance in OFRs is generally lower than in the atmosphere. Only at $\beta \sim 0$ may OFR185 theoretically attain a relative importance of $\mathrm{RO}_{2}+\mathrm{RO}_{2}$ of $\sim 70 \%$, as in the $\mathrm{P}_{1}$ case (pristine, but relatively high VOC; Fig. S5). Note that $\beta=0$ for all VOC oxidation (including oxidation of intermediates) is extremely unlikely. In OFR254, even if $\mathrm{RO}_{2}+\mathrm{RO}_{2}$ may contribute up to $\sim 100 \%$ to $\mathrm{RO}_{2}$ fate at very high $\mathrm{OHR}_{\text {ext }}$ at $\beta=0$, these conditions still also lead to significant $\mathrm{RO}_{2}+\mathrm{RO}_{2}$ in the fate of $\mathrm{RO}_{2}$ that self- and crossreacts more slowly, which is not atmospherically relevant.
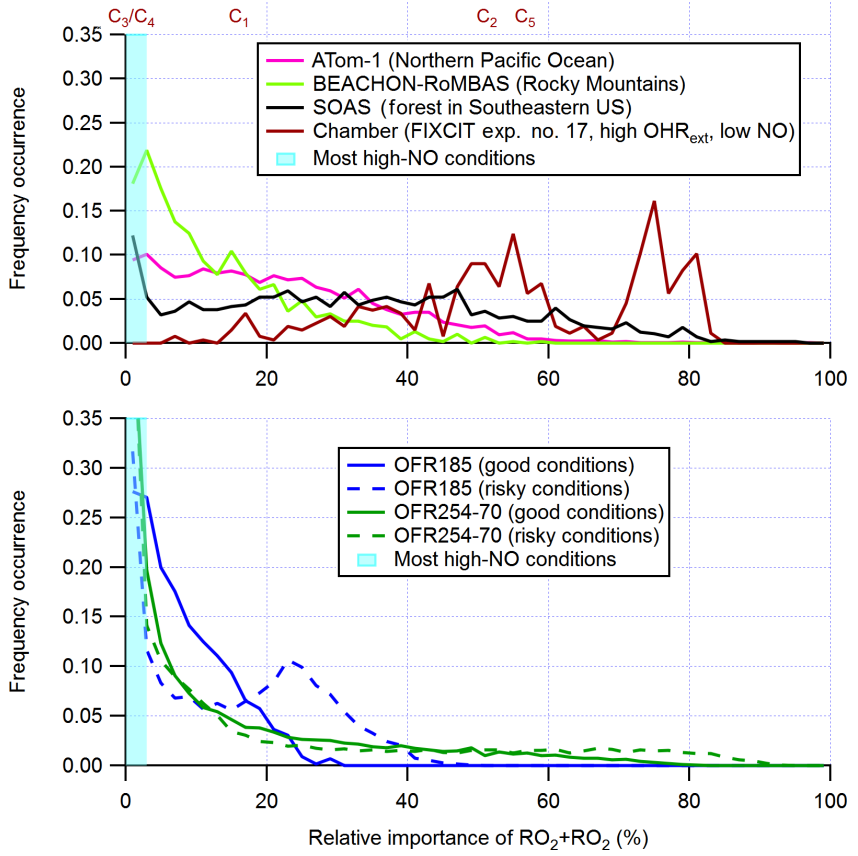

Figure 3. Frequency distributions of the relative importance of $\mathrm{RO}_{2}+\mathrm{RO}_{2}$ in the fate of $\mathrm{RO}_{2}$ (with fast self- and cross-reaction rate constant and without $\mathrm{RO}_{2}+\mathrm{OH}$ and $\mathrm{RO}_{2}$ isomerization considered) for OFR185 (including OFR185-iN $2 \mathrm{O}$ ), OFR254-70 (including OFR254-70-i $\mathrm{N}_{2} \mathrm{O}$ ), and a chamber experiment and in the atmosphere (a couple of different environments). The OFR distributions for good and risky conditions (in terms of $254 \mathrm{~nm}$ organic photolysis; see Table S1 for the definitions of these conditions) are shown separately. Also shown is the relative importance of $\mathrm{RO}_{2}+\mathrm{RO}_{2}$ for several typical chamber cases (see Table 2 for details on these cases). The range of the $\mathrm{RO}_{2}+\mathrm{RO}_{2}$ relative importance for most high-NO conditions is highlighted in cyan.

\subsubsection{Acyl $\mathrm{RO}_{2}$}

As described in Sect. 2.1, the generic acyl $\mathrm{RO}_{2}$ modeled in this study has the same loss pathways as $\mathrm{RO}_{2}$ with the fast self- and cross-reaction rate constant, except for $\mathrm{RO}_{2}+\mathrm{NO}_{2}$, which can be a significant acyl $\mathrm{RO}_{2}$ loss pathway in OFRs as well as both chambers and the atmosphere. When this reaction is included in the simulations of acyl $\mathrm{RO}_{2}$, it is a minor or negligible loss pathway of $\mathrm{RO}_{2}$ at low $\mathrm{N}_{2} \mathrm{O}$, while it can be the dominant fate of acyl $\mathrm{RO}_{2}$ at high $\mathrm{N}_{2} \mathrm{O}$ (Fig. 4). In general, the $\mathrm{RO}_{2}+\mathrm{NO}_{2}$ relative importance increases with initial $\mathrm{N}_{2} \mathrm{O}$. This is always true in OFR254-70- $\mathrm{iN}_{2} \mathrm{O}$ between $\mathrm{N}_{2} \mathrm{O}=0.02 \%$ and $\mathrm{N}_{2} \mathrm{O}=20 \%$, while in OFR $185-\mathrm{iN}_{2} \mathrm{O}$, the average relative contribution of $\mathrm{RO}_{2}+\mathrm{NO}_{2}$ to $\mathrm{RO}_{2}$ fate starts to decrease at $\mathrm{N}_{2} \mathrm{O} \sim 10 \%$ because $\mathrm{RO}_{2}+\mathrm{NO}$ regains some importance. This results from the $\mathrm{HO}_{x}$ suppression caused by high $\mathrm{NO}_{y}$ and strong $\mathrm{NO}$ production at high $\mathrm{N}_{2} \mathrm{O}$. Strong NO production increases its concentration and suppresses $\mathrm{HO}_{x}$ under these conditions, limiting the conversion of $\mathrm{NO}$ to $\mathrm{NO}_{2}$. Because of the strong $\mathrm{OH}$ suppression by high $\mathrm{NO}_{y}$ 


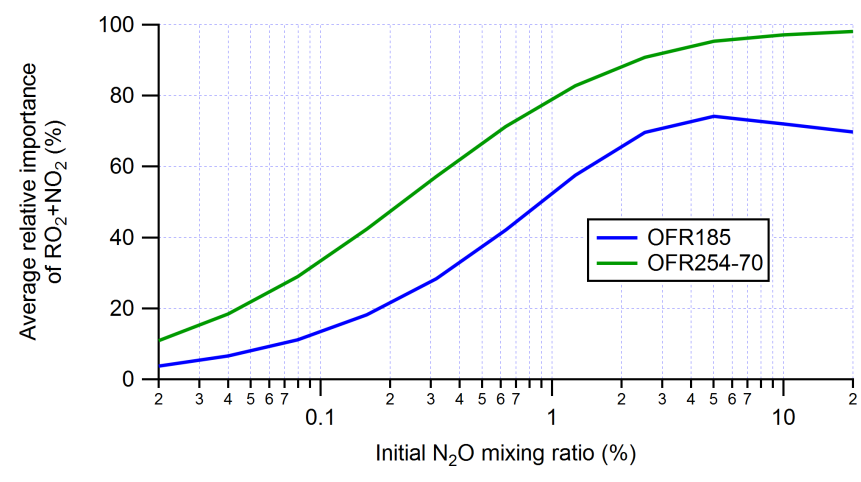

Figure 4. Average relative importance of $\mathrm{RO}_{2}+\mathrm{NO}_{2}$ in acyl $\mathrm{RO}_{2}$ fate $\left(\mathrm{RO}_{2}+\mathrm{OH}\right.$ and $\mathrm{RO}_{2}$ isomerization not considered) in OFR185 (including OFR185-iN ${ }_{2} \mathrm{O}$ ) and OFR254-70 (including OFR254-70$\mathrm{iN}_{2} \mathrm{O}$ ). The averages are calculated based on good and risky conditions (in terms of non-tropospheric organic photolysis) only.

at $\mathrm{N}_{2} \mathrm{O} \geq 10 \%$, these conditions are not desirable (Peng et al., 2018).

The only difference between the simulations of acyl $\mathrm{RO}_{2}$ and of the fast self- and cross-reacting non-acyl $\mathrm{RO}_{2}$ is the quasi-irreversible reaction $\mathrm{RO}_{2}+\mathrm{NO}_{2} \rightarrow \mathrm{RO}_{2} \mathrm{NO}_{2}$ at room temperature, whose effects are revealed by a comparison of the triangle plots of the $\mathrm{RO}_{2}$ fates in each case (Figs. 1b, d and S6). $\mathrm{RO}_{2}+\mathrm{NO}_{2}$ is clearly dominant in acyl $\mathrm{RO}_{2}$ fate in OFRs as long as $\mathrm{RO}_{2}+\mathrm{NO}$ plays some role (not necessarily under high-NO conditions). In OFR $185-\mathrm{iN}_{2} \mathrm{O}$, the relative importance of $\mathrm{RO}_{2}+\mathrm{RO}_{2}$ in the sum of the $\mathrm{HO}_{2}, \mathrm{NO}$ and $\mathrm{RO}_{2}$ pathways is reduced (Fig. S6a) compared to that of nonacyl $\mathrm{RO}_{2}$ with fast $\mathrm{RO}_{2}+\mathrm{RO}_{2}$ (Fig. 1b) because $\mathrm{RO}_{2}+\mathrm{NO}_{2}$ decreases acyl $\mathrm{RO}_{2}$ concentration. Such a decrease is not significant in OFR254-70-iN $2 \mathrm{O}$ (Fig. S6b, compared to Fig. 1d), since for non-acyl $\mathrm{RO}_{2}$, it is already stored in the form of $\mathrm{RO}_{2} \mathrm{NO}_{2}$ as an $\mathrm{RO}_{2}$ reservoir. In other words, the high initial $\mathrm{O}_{3}$ greatly accelerates $\mathrm{NO}$-to- $\mathrm{NO}_{2}$ oxidation and shifts the equilibrium $\mathrm{RO}_{2}+\mathrm{NO}_{2} \leftrightarrow \mathrm{RO}_{2} \mathrm{NO}_{2}$ far to the right even for non-acyl $\mathrm{RO}_{2}$.

$\mathrm{RO}_{2}+\mathrm{NO}_{2}$ is an inevitable and dominant sink of most acyl $\mathrm{RO}_{2}$ in high-NO $\mathrm{N}_{x}$ OFRs, though the extent of this dominance differs substantially among the different OFR operation modes. In OFR254-70- $\mathrm{iN}_{2} \mathrm{O}, \mathrm{RO}_{2}+\mathrm{NO}$ makes a minor or negligible contribution to acyl $\mathrm{RO}_{2}$ fate because the required high $\mathrm{O}_{3}$ very rapidly oxidizes $\mathrm{NO}$ to $\mathrm{NO}_{2}$ and leads to very low NO-to- $\mathrm{NO}_{2}$ ratios (e.g., $\sim 0.003-0.03$; see Fig. S7). In OFR185-iN $\mathrm{N}_{2} \mathrm{O}$, the contribution of $\mathrm{RO}_{2}+\mathrm{NO}$ can be somewhat significant, with typical NO-to- $\mathrm{NO}_{2}$ of $\sim$ 0.03-0.4. (Fig. S7). Urban NO-to- $\mathrm{NO}_{2}$ ratios vary widely, for example (roughly, and excluding significant tails in the frequency distributions) 0.02-1 for Barcelona and 0.007-0.7 for Los Angeles and Pittsburgh (see Fig. S7). Given these variations among different urban areas, $\mathrm{RO}_{2}+\mathrm{NO}$ and $\mathrm{RO}_{2}+\mathrm{NO}_{2}$ for acyl $\mathrm{RO}_{2}$ in OFR185-iN $\mathrm{O}_{2} \mathrm{O}$ can be regarded as relevant to urban atmospheres. Exceptions to the relevance of OFR185-
$\mathrm{iN}_{2} \mathrm{O}$ occur during morning rush hours (e.g., see the high NO-to- $\mathrm{NO}_{2}$ tail for the Pittsburgh case in Fig. S7), near major NO sources and/or in urban atmospheres with stronger NO emission intensity (e.g., Beijing, especially in winter; Fig. S7). In these cases, $\mathrm{NO}$-to- $\mathrm{NO}_{2}$ ratios may significantly exceed 1 , and $\mathrm{RO}_{2}+\mathrm{NO}$ may be the dominant acyl $\mathrm{RO}_{2}$ loss pathway. Such high-NO conditions appear difficult to simulate in OFRs with the current range of techniques.

Acyl $\mathrm{RO}_{2}$ is not the dominant type among $\mathrm{RO}_{2}$ types under most conditions in OFRs, chambers and the atmosphere, since their formation usually requires multistep (at least 2 steps) oxidation via specific pathways leading to an oxidized end group (i.e., aldehyde and then acylperoxy). However, simulations using the GECKO-A model in urban (Mexico City) and forested (Rocky Mountains) atmospheres (Fig. S8) show that acyl $\mathrm{RO}_{2}$ can still be a major (very roughly $1 / 3$ ) component of $\mathrm{RO}_{2}$ at ages of several hours or more. Therefore, acyl $\mathrm{RO}_{2}$ chemistry in a high-NO OFR can significantly deviate from that in an urban atmosphere with NO dominating $\mathrm{NO}_{x}$ and can be relevant to an urban atmosphere with $\mathrm{NO}_{2}$ dominating $\mathrm{NO}_{x}$. On the other hand, a few theoretical studies suggested that $\mathrm{H}$ abstraction by the acylperoxy radical site from hydroperoxy groups close to the acylperoxy site in multifunctional acyl $\mathrm{RO}_{2}$ may be extremely fast (Jørgensen et al., 2016; Knap and Jørgensen, 2017). If these theoretical predictions are sufficiently accurate, these acyl $\mathrm{RO}_{2}$ types may exclusively undergo an intramolecular $\mathrm{H}$ shift to form non-acyl $\mathrm{RO}_{2}$ or other radicals and prevent $\mathrm{RO}_{2}+\mathrm{NO}_{2}$ from occurring even at very high (ppm level) $\mathrm{NO}_{2}$. However, this type of $\mathrm{RO}_{2}$ is structurally specific and may not have strong impacts on the overall acyl $\mathrm{RO}_{2}$ chemistry.

\subsection{Simulations with all significant pathways}

Since $\mathrm{RO}_{2}$ isomerization does not significantly affect the generic $\mathrm{RO}_{2}$ concentration, the two $\mathrm{RO}_{2}$ fates that were recently found to be potentially important, i.e., $\mathrm{RO}_{2}+\mathrm{OH}$ and $\mathrm{RO}_{2}$ isomerization, can be discussed separately.

\subsection{1 $\mathrm{RO}_{2}+\mathrm{OH}$}

In the troposphere, $\mathrm{RO}_{2}+\mathrm{OH}$ is a minor (at low $\mathrm{NO}$ ) or negligible (at high NO) $\mathrm{RO}_{2}$ loss pathway (Fittschen et al., 2014; Assaf et al., 2016; Müller et al., 2016), as its rate constant is roughly an order of magnitude higher than that of $\mathrm{RO}_{2}+\mathrm{HO}_{2}$ (Table 1), while the ambient $\mathrm{OH}$ concentration is on average 2 orders of magnitude lower than that of $\mathrm{HO}_{2}$ (Mao et al., 2009; Stone et al., 2012; Fig. 5). We will not discuss $\mathrm{RO}_{2}+\mathrm{OH}$ in the high-NO cases in detail. Simply put, the relative importance of $\mathrm{RO}_{2}+\mathrm{OH}$ is generally negatively correlated with input $\mathrm{N}_{2} \mathrm{O}$ in OFR-i $\mathrm{N}_{2} \mathrm{O}$, as $\mathrm{NO}_{x}$ suppresses $\mathrm{OH}$ and the relative importance of $\mathrm{RO}_{2}+\mathrm{NO}$ increases. Below, we focus on low-NO (actually, for simplicity, zero-NO) conditions. 

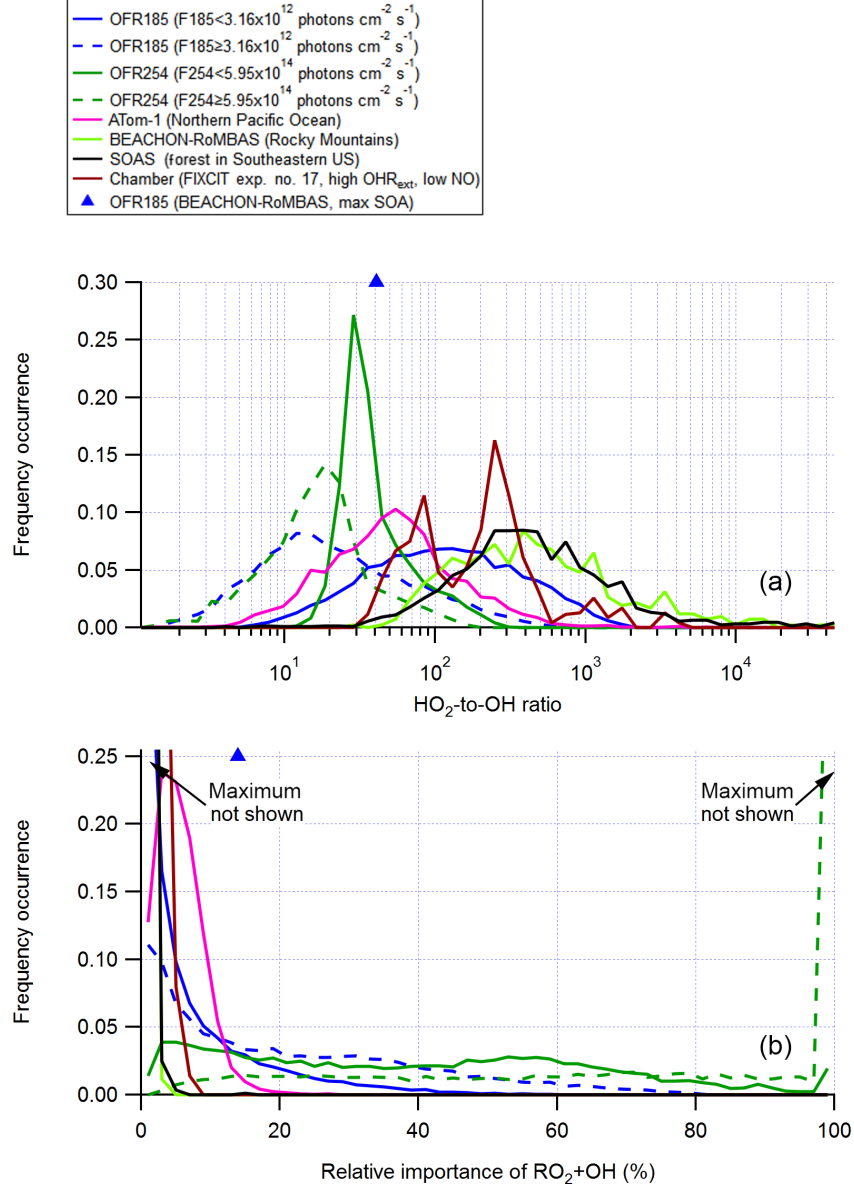

Figure 5. Frequency distributions of (a) the $\mathrm{HO}_{2}$-to- $\mathrm{OH}$ ratio and (b) the relative importance of $\mathrm{RO}_{2}+\mathrm{OH}$ in the fate of $\mathrm{RO}_{2}$ (with medium self- and cross-reaction rate constant) for OFR185 (including OFR185- $\mathrm{iN}_{2} \mathrm{O}$ ), OFR254-70 (including OFR254-70- $\mathrm{iN}_{2} \mathrm{O}$ ), and a chamber experiment and in the atmosphere (a couple of different environments). The OFR distributions for lower (F185 $<3.16 \times$ $10^{12}$ photons cm $\mathrm{cm}^{-2} \mathrm{~s}^{-1} ; \quad \mathrm{F} 254<5.95 \times 10^{14}$ photons $\mathrm{cm}^{-2} \mathrm{~s}^{-1}$ ) and higher UV $\left(\mathrm{F} 185 \geq 3.16 \times 10^{12}\right.$ photons $\mathrm{cm}^{-2} \mathrm{~s}^{-1}$; $\mathrm{F} 254 \geq 5.95 \times 10^{14}$ photons $\mathrm{cm}^{-2} \mathrm{~s}^{-1}$ ) are shown separately. Only good and risky conditions (in terms of non-tropospheric organic photolysis) are included in the distributions for OFRs. Also shown are the $\mathrm{HO}_{2}$-to-OH ratio and the relative importance of $\mathrm{RO}_{2}+\mathrm{OH}$ for an OFR experiment with ambient air input in a field study (BEACHON-RoMBAS; Palm et al., 2016).

At $\mathrm{N}_{2} \mathrm{O}=0$, it would be ideal if an $\mathrm{HO}_{2}$-to-OH ratio identical to the ambient values was realized in OFRs. In OFR185 cases with medium $\mathrm{RO}_{2}+\mathrm{RO}_{2}$, an $\mathrm{HO}_{2}$-to-OH ratio around 100 occurs at a combination of low $\mathrm{H}_{2} \mathrm{O}$ (of the order of $0.1 \%$ ), low $\mathrm{F} 185$ (of the order of $10^{11}$ photons $\mathrm{cm}^{-2} \mathrm{~s}^{-1}$ ) and medium $\mathrm{OHR}_{\text {ext }}\left(10-100 \mathrm{~s}^{-1}\right)$ and also at medium F185 ( $10^{12}$ photons $\mathrm{cm}^{-2} \mathrm{~s}^{-1}$ ) combined with very high $\mathrm{OHR}_{\mathrm{ext}}$ ( $\sim 1000 \mathrm{~s}^{-1}$, Fig. S9). Under both sets of conditions, relatively high external $\mathrm{OH}$ reactants suppress $\mathrm{OH}$, whose production is relatively weak, and convert some $\mathrm{OH}$ into $\mathrm{HO}_{2}$ through $\mathrm{HO}_{x}$ recycling in organic oxidation (e.g., via alkoxy radical chemistry). The reason why such an $\mathrm{OH}-\mathrm{to}-\mathrm{HO}_{2}$ conversion is needed to attain an ambient-like $\mathrm{HO}_{2}$-to-OH ratio is that OFR185 is unable to achieve this via the internal (mainly assisted by $\mathrm{O}_{3}$ ) interconversion of $\mathrm{HO}_{x}$. This inability is most evident when F185 $\left(10^{13}-10^{14}\right.$ photons $\left.\mathrm{cm}^{-2} \mathrm{~s}^{-1}\right)$ and $\mathrm{H}_{2} \mathrm{O}$ (of the order of $1 \%$ ) are high and $\mathrm{OHR}_{\text {ext }}$ is low $\left(<\sim 10 \mathrm{~s}^{-1}\right.$; Fig. S9). Under these conditions, OH production by $\mathrm{H}_{2} \mathrm{O}$ photolysis is so strong that the $\mathrm{HO}_{2}$-to- $\mathrm{OH}$ ratio is lowered to $\sim 1$, since $\mathrm{OH}$ and $\mathrm{H}$ (which recombines with $\mathrm{O}_{2}$ to form $\mathrm{HO}_{2}$ ) are produced in equal amounts from $\mathrm{H}_{2} \mathrm{O}$ photolysis. As the $\mathrm{RO}_{2}+\mathrm{OH}$ rate constant is only roughly 1 order of magnitude higher than that for $\mathrm{RO}_{2}+\mathrm{HO}_{2}$, slightly lower $\mathrm{HO}_{2}$-to-OH ratios (e.g., 30) suffice to keep $\mathrm{RO}_{2}+\mathrm{OH}$ minor in this case. A combination of $\mathrm{UV}$ and $\mathrm{H}_{2} \mathrm{O}$ that are not very high and a moderate $\mathrm{OHR}_{\text {ext }}$ that is able to convert some $\mathrm{OH}$ to $\mathrm{HO}_{2}$ and somewhat elevate the $\mathrm{HO}_{2}$-to$\mathrm{OH}$ ratio results in minor relative importance for $\mathrm{RO}_{2}+\mathrm{OH}$ (Figs. S9 and S10).

In OFR254-70, it is more difficult to reach an $\mathrm{HO}_{2}$-to$\mathrm{OH}$ ratio of $\sim 100$, which can only be realized at a combination of very low $\mathrm{H}_{2} \mathrm{O}$ and F254 ( 0.07\% and $\sim 5 \times$ $10^{13}$ photons $\mathrm{cm}^{-2} \mathrm{~s}^{-1}$, respectively) and very high $\mathrm{OHR}_{\mathrm{ext}}$ $\left(\sim 1000 \mathrm{~s}^{-1}\right)$. This is mainly due to high $\mathrm{O}_{3}$ in OFR25470 , which controls the $\mathrm{HO}_{x}$ interconversion through $\mathrm{HO}_{2}+$ $\mathrm{O}_{3} \rightarrow \mathrm{OH}+2 \mathrm{O}_{2}$ and $\mathrm{OH}+\mathrm{O}_{3} \rightarrow \mathrm{HO}_{2}+\mathrm{O}_{2}$ and makes both $\mathrm{OH}$ and $\mathrm{HO}_{2}$ more resilient to changes due to $\mathrm{OHR}_{\text {ext }}$ (Peng et al., 2015). Even without $\mathrm{H}_{2} \mathrm{O}$ photolysis at $185 \mathrm{~nm}$ as a major $\mathrm{HO}_{2}$ source, the $\mathrm{HO}_{x}$ interconversion controlled by $\mathrm{O}_{3}$ in OFR254-70 still brings the $\mathrm{HO}_{2}$-to-OH ratio to $\sim 1$ in the case of minimal external perturbation (see the region at the highest $\mathrm{H}_{2} \mathrm{O}$ and $\mathrm{UV}$ and $\mathrm{OHR}_{\text {ext }}=0$ in the OFR254-70 part of Fig. S9). This ratio cannot be easily elevated in OFR25470 because of the resilience of $\mathrm{OH}$ to suppression for this mode (Peng et al., 2015). Thus, this ratio is relatively low $(<30)$ under most conditions (Fig. S9), and consequently (and undesirably) $\mathrm{RO}_{2}+\mathrm{OH}$ is a major $\mathrm{RO}_{2}$ fate in OFR25470. There is an exception at relatively low $\mathrm{H}_{2} \mathrm{O}$ and UV with very high $\mathrm{OHR}_{\text {ext }}$ (Fig. S10); however, these conditions are undesirable in terms of non-tropospheric organic photolysis (Peng et al., 2016).

Only the results of $\mathrm{RO}_{2}$ with medium $\mathrm{RO}_{2}+\mathrm{RO}_{2}$ are discussed in this section. Those of $\mathrm{RO}_{2}$ with the fast $\mathrm{RO}_{2}+\mathrm{RO}_{2}$ are not shown as they are not qualitatively different. In OFR185, for the fast self- and cross-reacting $\mathrm{RO}_{2}, \mathrm{RO}_{2}+$ $\mathrm{RO}_{2}$ is relatively important at high $\mathrm{OHR}_{\text {ext }}\left(>\sim 100 \mathrm{~s}^{-1}\right.$; Fig. S3), while $\mathrm{RO}_{2}+\mathrm{OH}$ is a major $\mathrm{RO}_{2}$ fate at low $\mathrm{OHR}$ ext (generally of the order of $10 \mathrm{~s}^{-1}$ or lower) and relatively high $\mathrm{H}_{2} \mathrm{O}$ and UV (Fig. S10). These two ranges of conditions are relatively far away from each other, and hence there is no condition under which $\mathrm{RO}_{2}+\mathrm{RO}_{2}$ and $\mathrm{RO}_{2}+\mathrm{OH}$ are both major pathways that compete, which simplifies understanding $\mathrm{RO}_{2}$ fate. However, in OFR254-70, some conditions may lead to both significant $\mathrm{RO}_{2}+\mathrm{RO}_{2}$ (for the fast selfand cross-reacting $\mathrm{RO}_{2}$ ) and $\mathrm{RO}_{2}+\mathrm{OH}$ (e.g., $\mathrm{H}_{2} \mathrm{O} \sim 0.5 \%$, 
F254 1 $\times 10^{15}$ photons $\mathrm{cm}^{-2} \mathrm{~s}^{-1}$ and $\mathrm{OHR}_{\mathrm{ext}} \sim 100 \mathrm{~s}^{-1}$ ). Nevertheless, as long as $\mathrm{RO}_{2}+\mathrm{OH}$ plays a major role, these conditions do not bear much experimental interest and thus do not need to be discussed in detail.

\subsection{2 $\mathrm{RO}_{2}$ isomerization}

$\mathrm{RO}_{2}$ isomerization is a first-order reaction. For this type of reaction to occur, $\mathrm{RO}_{2}$ does not need any other species but only a sufficiently long lifetime against all other reactants combined, as most $\mathrm{RO}_{2}$ isomerization rate constants are $<10 \mathrm{~s}^{-1}$. Radical $\left(\mathrm{OH}, \mathrm{HO}_{2}\right.$, $\mathrm{NO}$, etc.) concentrations in OFRs are much higher than ambient levels and may shorten $\mathrm{RO}_{2}$ lifetimes compared to those in the troposphere. Possibly reduced $\mathrm{RO}_{2}$ lifetimes naturally raise concerns over the potentially diminished importance of $\mathrm{RO}_{2}$ isomerization in OFRs.

In this section we examine generic $\mathrm{RO}_{2}$ lifetimes against all reactions (calculated without $\mathrm{RO}_{2}$ isomerization taken into account) in OFR (including OFR-i $\mathrm{N}_{2} \mathrm{O}$ ) cases (for the medium $\mathrm{RO}_{2}+\mathrm{RO}_{2}$ case) and compare them with the $\mathrm{RO}_{2}$ lifetimes in recent major field and aircraft campaigns in relatively clean environments and a field campaign in an urban area (CalNex-LA), as well as a low-NO chamber experiment (Fig. 6). Indeed, $\mathrm{RO}_{2}$ lifetimes in clean ambient cases and in chambers with near-ambient radical levels are generally much longer than those in OFRs. The $\mathrm{RO}_{2}$ lifetime distribution of the explored good and risky cases in OFR254-70 (including OFR254-70-i $\mathrm{N}_{2} \mathrm{O}$ ) barely overlaps the ambient and chamber cases, while in OFR185 (including OFR185-iN ${ }_{2} \mathrm{O}$ ), the $\mathrm{RO}_{2}$ lifetime can be as long as $\sim 10 \mathrm{~s}$, which is longer than in urban areas and roughly at the lower end of the range of ambient $\mathrm{RO}_{2}$ lifetimes in clean environments (Fig. 6). The longest $\mathrm{RO}_{2}$ lifetime in OFR185 occurs at very low F185 (of the order of $10^{11}$ photons $\left.\mathrm{cm}^{-2} \mathrm{~s}^{-1}\right)$ and $\mathrm{H}_{2} \mathrm{O}(\sim 0.1 \%$; Fig. S11) when $\mathrm{HO}_{x}$ is low. In OFR254-70, for $\mathrm{RO}_{2}$ to survive for $\sim 10 \mathrm{~s}$, in addition to very low $\mathrm{UV}$ and $\mathrm{H}_{2} \mathrm{O}$, high $\mathrm{OHR}_{\text {ext }}$ is also needed (Fig. S11). High-OHR $\mathrm{ext}_{\text {conditions }}$ in OFR254-70 cause $\mathrm{OH}$ suppression and a decrease in $\mathrm{HO}_{x}$ concentration and hence result in relatively long $\mathrm{RO}_{2}$ lifetimes. However, the strong $\mathrm{OH}$ suppression is likely to create bad conditions (high contribution of non-tropospheric photolysis) (Peng et al., 2016). Low-OHR ext $_{\text {conditions do not }}$ lead to long $\mathrm{RO}_{2}$ lifetimes in OFR254-70 even at very low F254 and $\mathrm{H}_{2} \mathrm{O}$, since $\mathrm{O}_{3}$-assisted $\mathrm{HO}_{x}$ recycling prevents a very low $\mathrm{HO}_{x}$ level even if $\mathrm{HO}_{x}$ primary production is low (Peng et al., 2015)

$\mathrm{An} \mathrm{RO}_{2}$ lifetime (without $\mathrm{RO}_{2}$ isomerization included) of $10 \mathrm{~s}$ leads to a relative importance of isomerization of $50 \%$ in the total fate (including all loss pathways) of $\mathrm{RO}_{2}$ with an isomerization rate constant of $0.1 \mathrm{~s}^{-1}$, which is a typical order of magnitude for isomerization rate constants of multifunctional $\mathrm{RO}_{2}$ with hydroxyl and hydroperoxy substituents (Fig. 6; Crounse et al., 2013; D' Ambro et al., 2017; Praske et al., 2018). Although a $50 \%$ relative importance of isomeriza- tion under some OFR conditions is still lower than those in relatively low-NO ambient environments and low-NO chambers, this relative importance should certainly be deemed major and far from negligible as some have speculated (Crounse et al., 2013). Other monofunctional $\mathrm{RO}_{2}$ (with peroxy radical site only) and bifunctional $\mathrm{RO}_{2}$ with a peroxy radical site and a carbonyl group isomerize so slowly $\left(\sim 0.001-0.01 \mathrm{~s}^{-1}\right)$ that their isomerizations are minor or negligible loss pathways in the atmosphere, chambers and OFRs with $\mathrm{RO}_{2}$ lifetimes around $10 \mathrm{~s}$ (Fig. 6). Isomerizations of other types of multifunctional $\mathrm{RO}_{2}$ (e.g., multifunctional acyl $\mathrm{RO}_{2}$ with hydroxyl and hydroperoxy substituents at favorable positions) are extremely fast (rate constants up to $10^{6} \mathrm{~s}^{-1}$; Jørgensen et al., 2016; Knap and Jørgensen, 2017) and always dominate in their fates in the relatively low-NO atmosphere as well as in chambers and OFRs with $\mathrm{RO}_{2}$ lifetimes around $10 \mathrm{~s}$.

In the discussion about $\mathrm{RO}_{2}$ isomerization above (as in the $\mathrm{RO}_{2}+\mathrm{OH}$ exploration in Sect. 3.2.1), we only examine low-NO (or zero-NO for simplicity) conditions with medium $\mathrm{RO}_{2}+\mathrm{RO}_{2}$. In high-NO environments, e.g., polluted urban atmospheres with $\mathrm{NO}$ of at least $\sim 10 \mathrm{ppb}$ and high-NO OFRs in the $\mathrm{iN}_{2} \mathrm{O}$ modes, the $\mathrm{RO}_{2}$ lifetime is so short that isomerization is no longer a major fate for any but the most rapidly isomerizing multifunctional $\mathrm{RO}_{2}$ types discussed above. NO measured in Los Angeles during the CalNex-LA campaign (Ortega et al., 2016) was only $\sim 1 \mathrm{ppb}$, which would to allow $\mathrm{RO}_{2}$ to survive for a few seconds and isomerize (Fig. 6), even in an urban area.

The OFR simulations for the discussions about $\mathrm{RO}_{2}$ isomerization are the same as those conducted to study $\mathrm{RO}_{2}+$ $\mathrm{OH}$, i.e., the ones with medium $\mathrm{RO}_{2}+\mathrm{RO}_{2}$ and $\mathrm{RO}_{2}+\mathrm{OH}$ included. For fast $\mathrm{RO}_{2}$ self- and cross-reaction cases, $\mathrm{RO}_{2}$ lifetimes may be significantly shorter than for $\mathrm{RO}_{2}$ with the medium self- and cross-reaction rate constant at high $\mathrm{OHR}_{\text {ext }}$ $\left(>\sim 100 \mathrm{~s}^{-1}\right)$ in OFR185 (Fig. S3). These high-OHR ${ }_{\mathrm{ext}}$ conditions are likely to be risky or bad (of little experimental interest) (Peng et al., 2016) and thus do not need to be discussed further in detail. OFR254-70 (a zero-NO mode) does not generate good or risky (of at least some experimental interest in terms of non-tropospheric organic photolysis) conditions, also leading to low-NO-atmosphere-relevant $\mathrm{RO}_{2}$ lifetimes (Fig. 6). $\mathrm{RO}_{2}$ types with faster self- and cross-reaction rate constants have even shorter lifetimes in OFR254-70 and will not be discussed further.

\subsection{Guidelines for OFR operation}

In this section we discuss OFR operation guidelines for atmospherically relevant $\mathrm{RO}_{2}$ chemistry, with a focus on OFR185 and OFR254 (zero-NO modes). Since $\mathrm{RO}_{2}+\mathrm{HO}_{2}$ and $\mathrm{RO}_{2}+\mathrm{NO}$ both can vary from negligible to dominant $\mathrm{RO}_{2}$ fate in OFRs, chambers and the atmosphere (Figs. 1 and 2), these two pathways are not a concern in OFR atmospheric relevance considerations, and neither is $\mathrm{RO}_{2}+\mathrm{RO}_{2}$. Medium or slower $\mathrm{RO}_{2}+\mathrm{RO}_{2}$ is minor or negligible in the atmosphere 

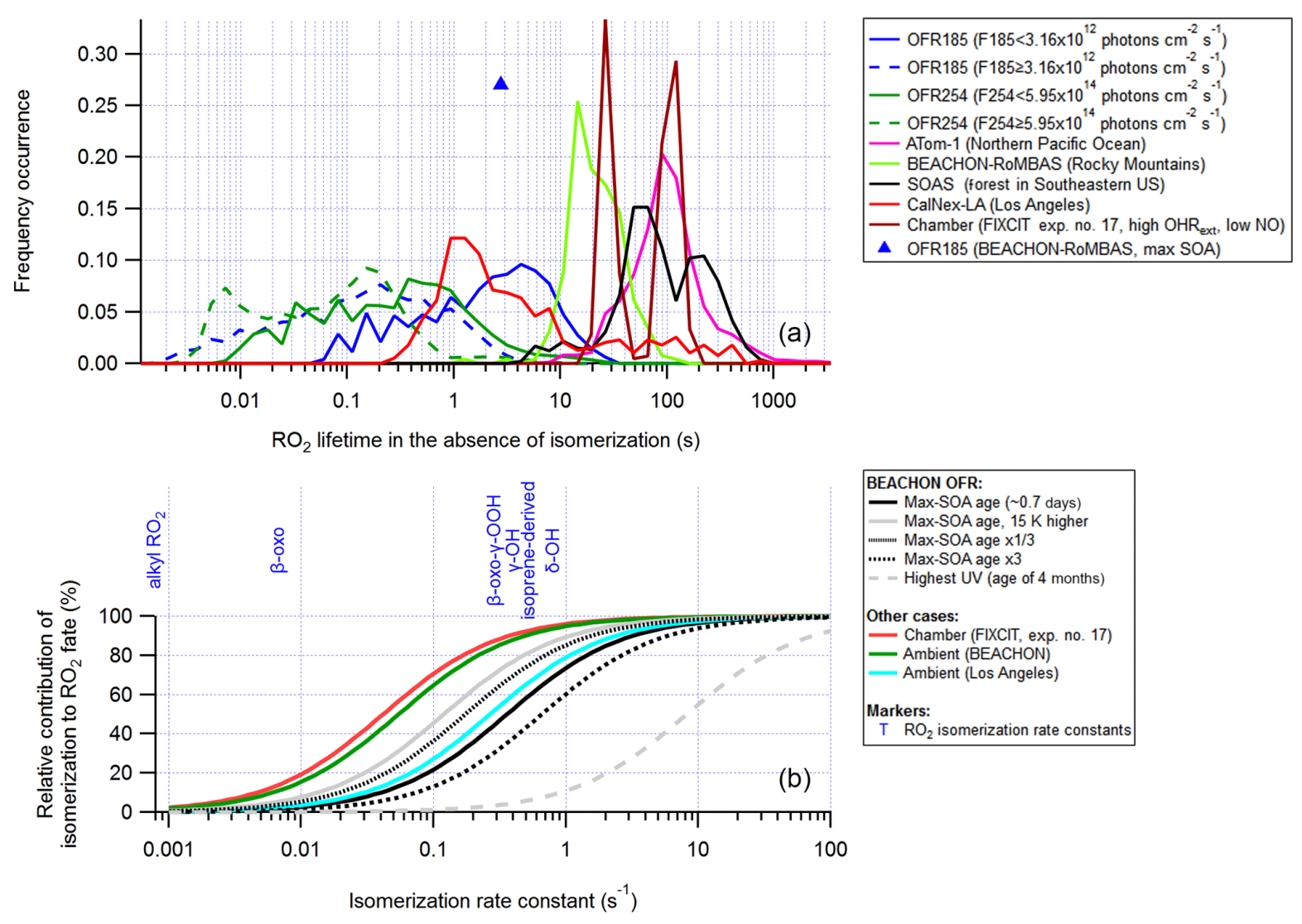

Figure 6. (a) Same format as Fig. 5, but for $\mathrm{RO}_{2}$ lifetime $\left(\mathrm{RO}_{2}\right.$ isomerization included in the model but excluded from lifetime calculation). (b) Relative contribution of isomerization to $\mathrm{RO}_{2}$ fate as a function of $\mathrm{RO}_{2}$ isomerization rate constant in several model cases for OFR experiments in the BEACHON-RoMBAS campaign (Palm et al., 2016), in a chamber experiment and in two ambient cases. Isomerization rate constants of several $\mathrm{RO}_{2}$ types (Crounse et al., 2013; Praske et al., 2018) are also shown.

and chambers, as well as in OFRs, as long as high OHR ext $_{\text {is }}$ avoided in OFR254 (Fig. S2). Fast $\mathrm{RO}_{2}+\mathrm{RO}_{2}$ is somewhat less important in OFRs than in the atmosphere (Figs. 1b, $\mathrm{d}$ and 3), but is still qualitatively atmospherically relevant, given the uncertainties associated with the $\mathrm{HO}_{x}$ recycling ratios of various reactive systems and the huge variety of $\mathrm{RO}_{2}$ types (and hence $\mathrm{RO}_{2}+\mathrm{RO}_{2}$ rate constants).

Accordingly, we focus on the atmospheric relevance of $\mathrm{RO}_{2}+\mathrm{OH}$ and $\mathrm{RO}_{2}$ isomerization, i.e., their relative contributions close to ambient values. Under typical high-NO conditions, $\mathrm{RO}_{2}+\mathrm{NO}$ dominates $\mathrm{RO}_{2}$ fate and $\mathrm{RO}_{2}+\mathrm{OH}$ is negligible. High $\mathrm{NO}$ also shortens the $\mathrm{RO}_{2}$ lifetime enough to effectively inhibit $\mathrm{RO}_{2}$ isomerization. Both the dominance of $\mathrm{RO}_{2}+\mathrm{NO}$ and the inhibition of $\mathrm{RO}_{2}$ isomerization also occur in the atmosphere and in chambers, so highNO OFR operation (typically NO $>10 \mathrm{ppb}$ ) represents these pathways realistically. Some care is, however, required with the $\mathrm{RO}_{2}+\mathrm{OH}$ and $\mathrm{RO}_{2}$ isomerization pathways at low $\mathrm{NO}$. Since $\mathrm{RO}_{2}+\mathrm{HO}_{2}$ in OFRs is always a major $\mathrm{RO}_{2}$ fate at low $\mathrm{NO}$ and $\mathrm{RO}_{2}+\mathrm{RO}_{2}$ is generally not problematic, $\mathrm{RO}_{2}+\mathrm{OH}$ and $\mathrm{RO}_{2}+\mathrm{HO}_{2}$ can be kept atmospherically relevant as long as the $\mathrm{HO}_{2}$-to- $\mathrm{OH}$ ratio is close to 100 (the ambient average). In addition, the $\mathrm{RO}_{2}$ lifetime (calculated without $\mathrm{RO}_{2}$ isomerization taken into account) should be at least around $10 \mathrm{~s}$.

Practically, $\mathrm{OH}$ production should be limited to achieve this goal. Too-strong $\mathrm{OH}$ production at high $\mathrm{H}_{2} \mathrm{O}$ and UV can elevate $\mathrm{OH}$ and $\mathrm{HO}_{2}$ concentrations, which shortens $\mathrm{RO}_{2}$ lifetime and decreases the $\mathrm{HO}_{2}$-to-OH ratio to $\sim 1$ (see Sect. 3.2.1). OH production is roughly proportional to both $\mathrm{H}_{2} \mathrm{O}$ and UV (Peng et al., 2015), so it can be limited by reducing either or both. However, $\mathrm{H}_{2} \mathrm{O}$ and UV have different effects on non-tropospheric organic photolysis. At a certain $\mathrm{OHR}_{\text {ext }}$, the $\mathrm{OH}$ production rate roughly determines the $\mathrm{OH}$ concentration in OFRs. Reducing UV decreases both $\mathrm{OH}$ and UV roughly proportionally (Peng et al., 2015), and hence changes in $\mathrm{F} 185_{\exp } / \mathrm{OH}_{\exp }$ and $\mathrm{F} 254_{\exp } / \mathrm{OH}_{\exp }$ are small (Peng et al., 2016); i.e., non-tropospheric organic photolysis does not become significantly worse if UV is reduced. By contrast, if $\mathrm{H}_{2} \mathrm{O}$ is reduced without also decreasing $\mathrm{UV}$, $\mathrm{F} 185_{\exp } / \mathrm{OH}_{\text {exp }}$ and $\mathrm{F} 254_{\exp } / \mathrm{OH}_{\exp }$ both increase, signifying a stronger relative importance of non-tropospheric pho- 
tolysis. Therefore, reducing UV is strongly preferred as an $\mathrm{OH}$ production limitation method and is effective in making both $\mathrm{RO}_{2}+\mathrm{OH}$ and $\mathrm{RO}_{2}$ isomerization more atmospherically relevant.

To further explore the effects of UV reduction on the $\mathrm{RO}_{2}+\mathrm{OH}$ (Fig. 5) and $\mathrm{RO}_{2}$ isomerization (Fig. 6) pathways, we divide our OFR case distributions into higher UV and lower UV classes, with the boundary being the midlevel (in logarithmic scale) UV in the explored range. The distributions for lower UV conditions (solid lines in Figs. 5 and 6) are clearly closer to the ambient cases (i.e., $\mathrm{HO}_{2}$-to-OH ratio closer to 100 , smaller $\mathrm{RO}_{2}+\mathrm{OH}$ relative importance and longer $\mathrm{RO}_{2}$ lifetime).

Since OFR254 is unable to achieve both conditions with at least some experimental interest (i.e., with sufficiently low non-tropospheric photolysis) and an atmospherically relevant $\mathrm{RO}_{2}$ lifetime, we now discuss preferable conditions for OFR185 only. As F185 close to or lower than $10^{12}$ photons $\mathrm{cm}^{-2} \mathrm{~s}^{-1}$ is needed for the $\mathrm{RO}_{2}$ lifetime to be around $10 \mathrm{~s}$ or longer (Fig. S11), the $\mathrm{OH}$ concentration under preferable conditions for atmospherically relevant $\mathrm{RO}_{2}$ chemistry ( $\sim 10^{9}$ molecules $\mathrm{cm}^{-3}$ or lower) is much lower than the maximum that OFR185 can physically reach $(\sim$ $10^{10}-10^{11}$ molecules $\mathrm{cm}^{-3}$ ). Furthermore, lower $\mathrm{OH}$ production leads to higher susceptibility to $\mathrm{OH}$ suppression by external OH reactants (Peng et al., 2015), which can create non-tropospheric photolysis problems (Peng et al., 2016). We thus recommend $\mathrm{H}_{2} \mathrm{O}$ as high as possible to maintain practically high $\mathrm{OH}$ while allowing lower UV to limit the importance of non-tropospheric organic photolysis.

The performance of various OFR185 conditions at high $\mathrm{H}_{2} \mathrm{O}(2.3 \%)$ is illustrated in Fig. 7 as a function of F185 and $\mathrm{OHR}_{\text {ext }}$. The three criteria for the performance, i.e., $\mathrm{RO}_{2}$ lifetime (calculated without $\mathrm{RO}_{2}$ isomerization considered), relative importance of $\mathrm{RO}_{2}+\mathrm{OH}$ and $\log \left(\mathrm{F} 254_{\exp } / \mathrm{OH}_{\exp }\right)$ (a measure of $254 \mathrm{~nm}$ non-tropospheric photolysis, which is usually worse than that at $185 \mathrm{~nm}$; Peng et al., 2016), are shown. At F185 of $\sim 10^{11}-10^{12}$ photons $\mathrm{cm}^{-2} \mathrm{~s}^{-1}$ and $\mathrm{OHR}_{\text {ext }}$ around or lower than $10 \mathrm{~s}^{-1}$, all three criteria are satisfied. Since UV (and hence OH production) is relatively low, a low $\mathrm{OHR}_{\text {ext }}\left(\sim 10 \mathrm{~s}^{-1}\right)$ is required to avoid heavy OH suppression and keep conditions good (green area in Fig. 7c). Nevertheless, risky conditions $\left(\log \left(\mathrm{F} 254_{\exp } / \mathrm{OH}_{\text {exp }}\right)<7\right.$; light red area in Fig. 7c) may also bear some experimental conditions depending on the type of VOC precursors (specifically on their reactivity toward $\mathrm{OH}$, their photolability at 185 and $254 \mathrm{~nm}$, and the same quantities for their oxidation intermediates; Peng et al., 2016; Peng and Jimenez, 2017). Thus, higher $\mathrm{OHR}_{\text {ext }}$ (up to $\sim 100 \mathrm{~s}^{-1}$ ) may also be considered in OFR experiments with some precursors (e.g., alkanes). In practice, the preferred conditions may require F185 even lower than that our lowest simulated lamp setting (Li et al., 2015). Such a low F185 may be realized, e.g., by partially blocking $185 \mathrm{~nm}$ photons using nontransparent lamp sleeves with evenly placed holes that allow for some $185 \mathrm{~nm}$ transmission.

Under these preferred conditions, $\mathrm{OH}$ concentration in OFR185 is $\sim 10^{9}$ molecules $\mathrm{cm}^{-3}$, equivalent to a photochemical age of $\sim 1$ eq. days for a typical residence time of $180 \mathrm{~s}$. This is much shorter than ages corresponding to the maximal oxidation capacity of OFRs (usually eq. weeks or months; Peng et al., 2015), but it is similar to the ages of the maximal organic aerosol formation in OFRs processing ambient air (Tkacik et al., 2014; Ortega et al., 2016; Palm et al., 2016). We show the maximal SOA formation case in the OFR185 experiments in the BEACHON-RoMBAS campaign in the Rocky Mountains (Palm et al., 2016) as an example (Figs. 5 and 6). During the campaign, relative humidity was high ( $>60 \%$ in most of the period), $\mathrm{OHR}_{\text {ext }}$ was estimated to be relatively low $\left(\sim 15 \mathrm{~s}^{-1}\right)$ in this forested area and UV in the OFR was limited in the case of the maximal SOA formation age ( $\sim 0.7$ eq. days). All these physical conditions were favorable for atmospherically relevant $\mathrm{RO}_{2}$ fate (Figs. 5 and 6). $\mathrm{RO}_{2}+\mathrm{OH}$ was minor in this case and the relative importance of $\mathrm{RO}_{2}$ isomerization in $\mathrm{RO}_{2}$ fate in the OFR was within a factor of $\sim 2$ of that in the atmosphere for all $\mathrm{RO}_{2}$ (regardless of the isomerization rate constant) during the BEACHON-RoMBAS campaign (Fig. 6). The effect of $\mathrm{UV}$ on the relative importance of $\mathrm{RO}_{2}$ isomerization for this example is also illustrated in Fig. 6. In the sensitivity case with a lower age, lower UV results in a larger contribution of isomerization to $\mathrm{RO}_{2}$ fate, while the relative importance of $\mathrm{RO}_{2}$ isomerization is lower in a sensitivity case with an age 3 times that of the maximal SOA formation. In an extreme sensitivity case with the highest UV in the range of this study (with an age of 4 eq. months), $\mathrm{RO}_{2}$ isomerization becomes minor or negligible for all $\mathrm{RO}_{2}$ except extremely rapidly isomerizing ones.

The discussions above indicate that the atmospheric relevance of gas-phase $\mathrm{RO}_{2}$ chemistry in OFRs deteriorates as the photochemical age over the whole residence time (180 s) increases. To reach longer ages, longer residence times (with UV still being low) can be adopted. However, OFR residence times $>10 \mathrm{~min}$ tend to be limited by the increasing importance of wall losses (Palm et al., 2016). As a result, longer residence times can only increase photochemical age in OFRs up to about a week. This implies that in OFR cases with ages much higher than that of maximal SOA formation (corresponding to the heterogeneous oxidation stage of $\mathrm{SOA}$ ), the atmospheric relevance of gas-phase $\mathrm{RO}_{2}$ chemistry in the SOA formation stage (before the age of maximal SOA formation) often cannot be ensured. However, under those conditions new SOA formation is typically not observed, and the dominant process affecting OA is heterogeneous oxidation of the preexisting OA (Palm et al., 2016). If the heterogeneous oxidation of newly formed SOA is of interest, a two-stage solution may be required. Lower UV can be used in the SOA formation stage to keep the atmospheric relevance of the gas-phase chemistry, while high UV 


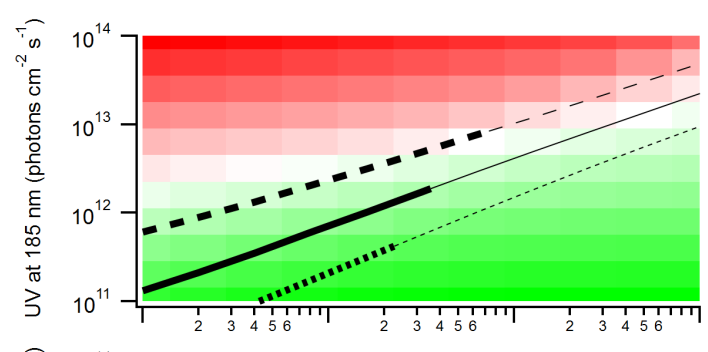

(a)
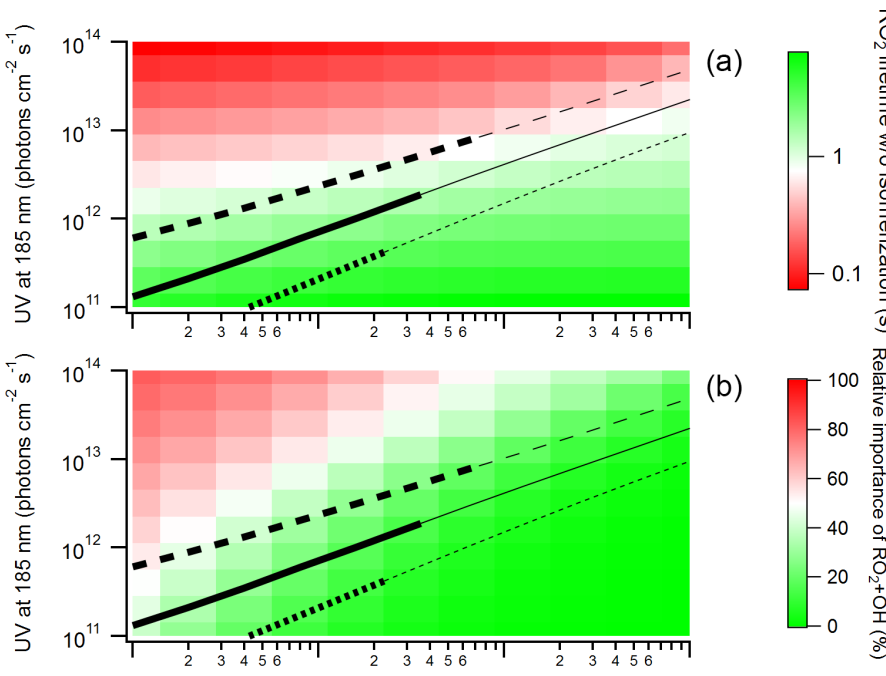

(b)

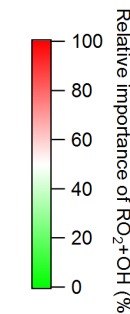

OH (molecules $\mathrm{cm}^{-3}$ ):
$\cdots+\cdots 3 \times 16 \times 10^{8}$
$-1 \times 10^{9}$
$-\quad 3.16 \times 10^{9}$
Thick lines:
good conditions
(for $254 \mathrm{~nm}$ photolysis)
Thin lines:
risky conditions
(for $254 \mathrm{~nm}$ photolysis)

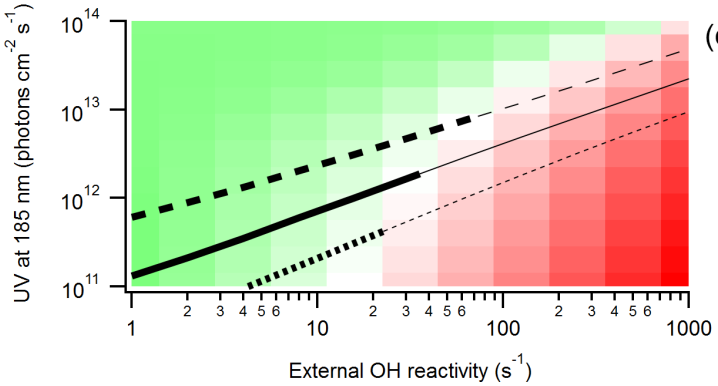

(c)

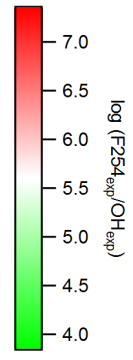

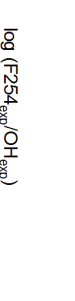

Figure 7. (a) $\mathrm{RO}_{2}$ lifetime in the absence of isomerization, (b) relative importance of $\mathrm{RO}_{2}+\mathrm{OH}$ in $\mathrm{RO}_{2}$ fate, and (c) logarithm of the exposure ratio between $254 \mathrm{~nm}$ photon flux and $\mathrm{OH}$ as a function of $185 \mathrm{~nm}$ photon flux and external $\mathrm{OH}$ reactivity for $\mathrm{OFR} 185$ at $\mathrm{N}_{2} \mathrm{O}=0$ and $\mathrm{H}_{2} \mathrm{O}=2.3 \%$. Three lines denoting conditions leading to $\mathrm{OH}$ of $3.16 \times 10^{8}, 1 \times 10^{9}$ and $3.16 \times 10^{9}$ molecules $\mathrm{cm}^{-3}$ are added in each panel. The thick and thin parts of these lines correspond to good and risky conditions (in terms of 254 nm organic photolysis, which is usually worse than $185 \mathrm{~nm}$ organic photolysis; Peng et al., 2016), respectively.

can be used in the heterogeneous aging stage to reach a high equivalent age. The latter approach is viable since heterogeneous oxidation of SOA by $\mathrm{OH}$ is slow and particle-phase chemistry is not strongly affected by gas-phase species except $\mathrm{OH}$ when $\mathrm{OH}$ is very high (Richards-Henderson et al., 2015, 2016; Hu et al., 2016). This two-stage solution may be realized through a cascade-OFR system or UV sources at different intensities within an OFR (e.g., spliced lamps).

Praske et al. (2018) measured $\mathrm{RO}_{2}$ isomerization rate constants at 296 and $318 \mathrm{~K}$ and observed an increase in the rate constants by a factor of $\sim 5$ on average. A $15 \mathrm{~K}$ temperature increase in OFRs would lead to $\mathrm{RO}_{2}$ isomerization being accelerated by a factor of $\sim 3$, while other major gas-phase radical reactions have weak or no temperature dependence (e.g., $\sim 7 \%, \sim 5 \%, \sim 6 \%$ and $\sim 19 \%$ slowdowns for isoprene $+\mathrm{OH}$, toluene $+\mathrm{OH}$, typical $\mathrm{RO}_{2}+\mathrm{NO}$ and $\mathrm{RO}_{2}+\mathrm{HO}_{2}$, respectively; Atkinson and Arey, 2003; Ziemann and Atkinson, 2012). As a consequence, the relative importance of $\mathrm{RO}_{2}$ isomerization in $\mathrm{RO}_{2}$ fate in OFRs can be elevated and closer to atmospheric values (Fig. 6). Nevertheless, a $15 \mathrm{~K}$ increase in temperature may also result in some OA evaporation (Huffman et al., 2009; Nault et al.,
2018). Besides, the reduction of acylperoxy nitrate formation in OFRs, which may be useful to mimic some urban environments where $\mathrm{NO}$ plays a larger role in acyl $\mathrm{RO}_{2}$ fate (see Sect. 3.1.2), is unlikely to be achieved by increasing OFR temperature. The $\mathrm{O}-\mathrm{N}$ bond energy of acylperoxy nitrates is $\sim 28 \mathrm{kcal} \mathrm{mol}^{-1}$ (Orlando and Tyndall, 2012), which can be taken as an approximate reaction energy of their decomposition. Then a $20 \mathrm{~K}$ temperature increase results in the equilibrium constant of acyl $\mathrm{RO}_{2}+\mathrm{NO}_{2} \leftrightarrow$ acyl $\mathrm{RO}_{2} \mathrm{NO}_{2}$ being shifted toward $\mathrm{RO}_{2}+\mathrm{NO}_{2}$ by a factor of $\sim 20$. However, this shift is still too small relative to the equilibrium constant itself. It can be deduced by a simple calculation that for the generic acyl $\mathrm{RO}_{2}$ in this study in an OFR at $318 \mathrm{~K}\left(20 \mathrm{~K}\right.$ higher than room temperature) with $\mathrm{NO}_{2}$ of $10^{12}$ molecules $\mathrm{cm}^{-3}$ (a relatively low level in typical OFR$\mathrm{iN}_{2} \mathrm{O}$ experiments; Peng et al., 2018), $\sim 0.1 \%$ of the total amount of acyl $\mathrm{RO}_{2}+$ acyl $\mathrm{RO}_{2} \mathrm{NO}_{2}$ will be present in the form of acyl $\mathrm{RO}_{2}$. Even if acylperoxy nitrate decomposition is 20 times faster than at room temperature and the formed acyl $\mathrm{RO}_{2}$ can irreversibly react with $\mathrm{NO}$ and decrease the acylperoxy nitrate concentration, this effect is small: typically up to an approximate $20 \%$ decrease in acylperoxy ni- 
trate and usually negligible changes in $\mathrm{NO}$ and $\mathrm{NO}_{2}$. The minor effect is due to (i) an acylperoxy concentration that is still very low, (ii) an NO concentration that is much lower than $\mathrm{NO}_{2}$ and (iii) an acylperoxy nitrate decomposition lifetime that is still of the order of minutes.

As discussed above, high $\mathrm{H}_{2} \mathrm{O}$, low $\mathrm{UV}$ and low $\mathrm{OHR}_{\text {ext }}$ are recommended for keeping the atmospheric relevance of $\mathrm{RO}_{2}$ chemistry in OFRs. These three requirements are also part of the requirements for attaining good high-NO conditions in OFR185-iNO (the OFR185 mode with initial NO injection; Peng and Jimenez, 2017). In addition to these three, an initial NO of several tens of ppb is also needed to obtain a good high-NO condition in OFR185-iNO. Under these conditions, $\mathrm{RO}_{2}+\mathrm{NO}$ dominates over $\mathrm{RO}_{2}+\mathrm{HO}_{2}$ and hence $\mathrm{RO}_{2}+\mathrm{OH}$; UV is low, the photochemical age is typically $\sim 1$ eq. days and the $\mathrm{RO}_{2}$ lifetime can be a few seconds. Therefore, these conditions are a good fit for studying the environments in relatively clean urban areas, such as Los Angeles during CalNex-LA (Ortega et al., 2016), where NO is high enough that the dominant bimolecular fate of $\mathrm{RO}_{2}$ is $\mathrm{RO}_{2}+\mathrm{NO}$ but low enough to maintain $\mathrm{RO}_{2}$ lifetimes that allow for the most common $\mathrm{RO}_{2}$ isomerizations.

As $\mathrm{RO}_{2}$ fate in OFRs is a highly complex problem and it can be tricky to find suitable physical conditions to simultaneously achieve experimental goals and keep the atmospheric relevance of the chemistry in OFRs, we provide here an OFR $\mathrm{RO}_{2}$ Fate Estimator (in the Supplement) to qualitatively aid experimental planning. The $\mathrm{OFR}_{\mathrm{RO}_{2}}$ Fate Estimator couples the OFR Exposure Estimator (Peng et al., 2016, 2018) to a general $\mathrm{RO}_{2}$ fate estimator (also in the Supplement; see Fig. S12 for a screenshot of its layout). The OFR Exposure Estimator updated in this study also contains estimation equations for the $\mathrm{HO}_{2}$-to-OH ratio in OFR185 (in OFR254, $\mathrm{RO}_{2}$ fate is always atmospherically irrelevant at low NO, while at high $\mathrm{NO}, \mathrm{RO}_{2}+\mathrm{NO}$ dominates and a detailed $\mathrm{RO}_{2}$ fate analysis is no longer needed). In the general $\mathrm{RO}_{2}$ fate estimator, all $\mathrm{RO}_{2}$ reactant concentrations and all $\mathrm{RO}_{2}$ loss pathway rate constants can be specified. Thus, the general $\mathrm{RO}_{2}$ fate estimator can also be applied to the atmosphere and chamber experiments, in addition to OFRs. When applied to OFRs, the general $\mathrm{RO}_{2}$ fate estimator is provided by the OFR $\mathrm{RO}_{2}$ Fate Estimator with quantities estimated in the OFR Exposure Estimator (e.g., $\mathrm{OH}$ and $\mathrm{NO}$ ). $\mathrm{RO}_{2}$ concentration and fate are calculated according to Appendix $\mathrm{B}$ in the $\mathrm{RO}_{2}$ fate estimators.

\section{Conclusions}

We investigated $\mathrm{RO}_{2}$ chemistry in OFRs with an emphasis on its atmospheric relevance. All potentially major loss pathways of $\mathrm{RO}_{2}$, i.e., reactions of $\mathrm{RO}_{2}$ with $\mathrm{HO}_{2}, \mathrm{NO}$ and $\mathrm{OH}$, of acyl $\mathrm{RO}_{2}$ with $\mathrm{NO}_{2}$, and self- and cross-reactions of $\mathrm{RO}_{2}$ and $\mathrm{RO}_{2}$ isomerization, were studied and their relative importances in $\mathrm{RO}_{2}$ fate were compared to those in the at- mosphere and chamber experiments. OFRs were shown to be able to tune the relative importance of $\mathrm{RO}_{2}+\mathrm{HO}_{2}$ vs. $\mathrm{RO}_{2}+\mathrm{NO}$ by injecting different amounts of $\mathrm{N}_{2} \mathrm{O}$. For many $\mathrm{RO}_{2}$ types (including all unsubstituted non-acyl $\mathrm{RO}_{2}$ and substituted secondary and tertiary $\mathrm{RO}_{2}$ ), their self-reactions and the cross-reaction between them are minor or negligible in the atmosphere and chambers. This is also the case in OFR185 (including OFR185-i ${ }_{2} \mathrm{O}$ ) and OFR254-i $\mathrm{N}_{2} \mathrm{O}$; however, those $\mathrm{RO}_{2}$ self- and cross-reactions can be important at high precursor concentrations $\left(\mathrm{OHR}_{\mathrm{ext}}>100 \mathrm{~s}^{-1}\right)$ in OFR254. For substituted primary $\mathrm{RO}_{2}$ and acyl $\mathrm{RO}_{2}$, their self- and cross-reactions (including the ones with $\mathrm{RO}_{2}$ whose self-reaction rate constants are slower) can play an important role in $\mathrm{RO}_{2}$ fate in the atmosphere and chambers and may also be major $\mathrm{RO}_{2}$ loss pathways in OFRs, although they are somewhat less important in OFRs than in the atmosphere. Acylperoxy nitrates are the dominant sink of acyl $\mathrm{RO}_{2}$ at high $\mathrm{NO}_{x}$ in OFRs (particularly in OFR254-iN $2 \mathrm{O}$ for which $\mathrm{RO}_{2}+\mathrm{NO}$ is negligible for acylperoxy loss), while there is only a minor reservoir of acyl $\mathrm{RO}_{2}$ in the atmosphere under most conditions except in urban atmospheres, where $\mathrm{RO}_{2}+\mathrm{NO}$ and $\mathrm{RO}_{2}+\mathrm{NO}_{2}$ can both be the dominant acylperoxy loss pathway depending on conditions. In chambers, most acyl $\mathrm{RO}_{2}$ can be stored in the form of acylperoxy nitrates if $\mathrm{NO}_{2}$ is very high (hundreds of ppb to ppm level).

Besides the abovementioned well-known pathways, $\mathrm{RO}_{2}+\mathrm{OH}$ and $\mathrm{RO}_{2}$ isomerization may also play an important role in $\mathrm{RO}_{2}$ fate and sometimes results in atmospherically irrelevant $\mathrm{RO}_{2}$ chemistry in OFRs. Here we summarize the main findings about all the pathways and the related guidelines for OFR operation.

- Under typical high-NO conditions, $\mathrm{RO}_{2}+\mathrm{NO}$ dominates $\mathrm{RO}_{2}$ fate and the $\mathrm{RO}_{2}$ lifetime is too short to allow for most $\mathrm{RO}_{2}$ isomerizations, regardless of whether in the atmosphere, chambers or OFRs, thus raising no concern about the atmospheric relevance of the OFR $\mathrm{RO}_{2}$ chemistry.

- Under low-NO conditions, OFR254 cannot yield any physical conditions leading to a sufficiently long $\mathrm{RO}_{2}$ lifetime for its isomerization because of the high radical levels and their resilience to external perturbations in OFR254.

- In OFR185 with strong OH production (and hence high $\mathrm{OH}), \mathrm{RO}_{2}+\mathrm{OH}$ and $\mathrm{RO}_{2}$ isomerization may strongly deviate from that in the atmosphere (becoming important and negligible, respectively, for relatively rapidly isomerizing $\mathrm{RO}_{2}$; rate constants of the order of $0.1 \mathrm{~s}^{-1}$ ).

- To attain both atmospherically relevant VOC and $\mathrm{RO}_{2}$ chemistries, OFR185 requires high $\mathrm{H}_{2} \mathrm{O}$, low $\mathrm{UV}$ and low $\mathrm{OHR}_{\text {ext }}$. These conditions ensure minor or negligible $\mathrm{RO}_{2}+\mathrm{OH}$ and a relative importance of $\mathrm{RO}_{2}$ isomerization in $\mathrm{RO}_{2}$ fate in OFRs within a factor of $\sim 2$ of that in the atmosphere. 
- Under conditions allowing both VOC and $\mathrm{RO}_{2}$ chemistries to be atmospherically relevant, the maximal photochemical age that can be reached is limited to a few eq. days. This age roughly covers the period required for maximum SOA formation in ambient air.

- To most realistically study much higher ages for SOA functionalization and fragmentation by heterogeneous oxidation, a sequence of low-UV SOA formation followed by a high UV condition (in the same reactor or in cascade reactors) may be needed.

- High $\mathrm{H}_{2} \mathrm{O}$, low UV and low $\mathrm{OHR}_{\text {ext }}$ in the OFR185iNO mode can achieve conditions relevant to clean urban atmosphere, i.e., high NO but not sufficiently high to inhibit common $\mathrm{RO}_{2}$ isomerization.

Finally, $\mathrm{RO}_{2}$ chemistry is not only highly complex but also plays a central and instrumental role in atmospheric chemistry, in particular VOC oxidation and SOA formation. For all experiments conducted with an atmospheric chemistry simulation apparatus (chamber, flow reactor, etc.), an atmospherically relevant $\mathrm{RO}_{2}$ chemistry is crucial to meaningful experimental results. However, most literature studies have not published experimental data that are sufficient for estimating $\mathrm{RO}_{2}$ fate. The FIXCIT chamber experiment campaign is one of the few exceptions for which comprehensive data were reported (Nguyen et al., 2014) and used for the $\mathrm{RO}_{2}$ fate analysis in the present work. We recommend measuring and/or estimating and reporting $\mathrm{OH}, \mathrm{HO}_{2}, \mathrm{NO}, \mathrm{NO}_{2}$ and $\mathrm{OHR}$ VOC (or initial precursor composition at least) whenever possible for all future atmospheric laboratory and field experiments for organic oxidation to facilitate the analysis of $\mathrm{RO}_{2}$ fate and the evaluation of its atmospheric relevance.
Data availability. The latest version of the general $\mathrm{RO}_{2}$ fate estimator and $\mathrm{OFR} \mathrm{RO}_{2}$ Fate Estimator can be downloaded from https: //sites.google.com/site/pamwiki/hardware/estimation-equations (last access: 17 January 2019). The model outputs in this study are available from the authors upon request (zhe.peng@colorado.edu or jose.jimenez@colorado.edu). All data shown in the figures in this paper (including the Supplement) can be downloaded from http://cires1.colorado.edu/jimenez/group_pubs.html (last access: 17 January 2019). 

Appendix A: Glossary of the acronyms (except field
campaign names) used in the paper.

\begin{tabular}{|c|c|}
\hline DFR & oxidation flow reactor \\
\hline VOC & volatile organic compound \\
\hline SOA & secondary organic aerosol \\
\hline $\mathrm{H}_{2} \mathrm{O}$ & water vapor mixing ratio \\
\hline $\mathrm{OHR}_{\mathrm{ext}}$ & $\begin{array}{l}\text { external OH reactivity (due to } \mathrm{CO} \\
\mathrm{SO}_{2} \text {, VOCs, etc.) }\end{array}$ \\
\hline PAM & $\begin{array}{l}\text { potential aerosol mass, a specific } \\
\text { type of OFR }\end{array}$ \\
\hline OFR185 & $\begin{array}{l}\text { oxidation flow reactor using both } \\
185 \text { and } 254 \mathrm{~nm} \text { light }\end{array}$ \\
\hline OFR254 & $\begin{array}{l}\text { oxidation flow reactor using } \\
254 \mathrm{~nm} \text { light only }\end{array}$ \\
\hline OFR254-X & $\begin{array}{l}\text { OFR254 with } X \text { ppm } \mathrm{O}_{3} \text { initially } \\
\text { injected }\end{array}$ \\
\hline $\mathrm{OFR}-\mathrm{iN} \mathrm{N}_{2} \mathrm{O}$ & OFR with $\mathrm{N}_{2} \mathrm{O}$ initially injected \\
\hline OFR185-iN $2 \mathrm{O}$ & $\begin{array}{l}\text { OFR185 with } \mathrm{N}_{2} \mathrm{O} \text { initially in } \\
\text { jected }\end{array}$ \\
\hline $\mathrm{OFR} 254-\mathrm{iN}_{2} \mathrm{O}$ & $\begin{array}{l}\text { OFR254 with } \mathrm{N}_{2} \mathrm{O} \text { initially in } \\
\text { jected }\end{array}$ \\
\hline $\mathrm{OFR} 254-\mathrm{X}-\mathrm{iN}_{2} \mathrm{O}$ & $\begin{array}{l}\text { OFR254-X with } \mathrm{N}_{2} \mathrm{O} \text { initially in } \\
\text { jected }\end{array}$ \\
\hline $\mathrm{OHR}_{\mathrm{VOC}}$ & $\mathrm{OH}$ reactivity due to VOCs \\
\hline F185, F254, etc. & $\begin{array}{l}\text { UV photon flux at } 185 \mathrm{~nm} \\
254 \mathrm{~nm} \text {, etc. }\end{array}$ \\
\hline $\mathrm{N}_{2} \mathrm{O}$ & $\mathrm{N}_{2} \mathrm{O}$ mixing ratio \\
\hline $\mathrm{OH}_{\text {exp }}, \mathrm{F} 185_{\mathrm{exp}}$, etc. & $\begin{array}{l}\text { exposure (integral over time) } \\
\mathrm{OH}, \mathrm{F} 185 \text {, etc. }\end{array}$ \\
\hline
\end{tabular}

\section{Appendix B: Steady-state approximation for generic $\mathrm{RO}_{2}$}

The production rate of a generic $\mathrm{RO}_{2}$ is almost identical to the VOC consumption rate, since the second step of the conversion chain $\mathrm{VOC} \rightarrow \mathrm{R} \rightarrow \mathrm{RO}_{2}$ is extremely fast. Therefore, the generic $\mathrm{RO}_{2}$ production rate, $P$, can be expressed as follows:

$P=\sum_{i} k_{i} c_{i} \cdot \mathrm{OH}=\mathrm{OHR}_{\mathrm{VOC}} \cdot \mathrm{OH}$,

where $\mathrm{OH}$ is $\mathrm{OH}$ concentration and $c_{i}$ and $k_{i}$ are respectively the concentration and the reaction rate constant with $\mathrm{OH}$ of the $i$ th VOC. OHR VOC is the total OHR due to VOC and equal to $\Sigma_{i} k_{i} c_{i}$ by definition.
For the generic $\mathrm{RO}_{2}$ loss rate, the reactions of $\mathrm{RO}_{2}$ with $\mathrm{HO}_{2}, \mathrm{NO}, \mathrm{RO}_{2}, \mathrm{NO}_{2}$ (for acyl $\mathrm{RO}_{2}$ only) and $\mathrm{OH}$ are considered. Isomerization generally does not lead to a total $\mathrm{RO}_{2}$ concentration decrease and is thus not included in its loss rate. Then the $\mathrm{RO}_{2}$ loss rate is

$$
\begin{aligned}
L= & k_{\mathrm{HO}_{2}} \mathrm{RO}_{2} \cdot \mathrm{HO}_{2}+k_{\mathrm{NO}} \mathrm{RO}_{2} \cdot \mathrm{NO}+2 k_{\mathrm{RO}_{2}} \mathrm{RO}_{2} \cdot \mathrm{RO}_{2} \\
& +k_{\mathrm{NO}_{2}} \mathrm{RO}_{2} \cdot \mathrm{NO}_{2}+k_{\mathrm{OH}} \mathrm{RO}_{2} \cdot \mathrm{OH},
\end{aligned}
$$

where $\mathrm{RO}_{2}, \mathrm{HO}_{2}, \mathrm{NO}, \mathrm{NO}_{2}$ and $\mathrm{OH}$ are the concentrations of corresponding species and $k_{A}\left(A=\mathrm{RO}_{2}, \mathrm{HO}_{2}, \mathrm{NO}, \mathrm{NO}_{2}\right.$ and $\mathrm{OH})$ is the reaction rate constant of $\mathrm{RO}_{2}$ with $A$. For non-acyl $\mathrm{RO}_{2}$, the term $k_{\mathrm{NO}_{2}} \mathrm{RO}_{2} \cdot \mathrm{NO}_{2}$ is not included; for cases with well-known pathways only $\left(\mathrm{RO}_{2}+\mathrm{HO}_{2}, \mathrm{RO}_{2}+\mathrm{RO}_{2}, \mathrm{RO}_{2}+\right.$ $\mathrm{NO}$ and $\mathrm{RO}_{2}+\mathrm{NO}_{2}$; see Sect. 3.1), the term $k_{\mathrm{OH}} \mathrm{RO}_{2} \cdot \mathrm{OH}$ is excluded. $k_{\mathrm{RO}_{2}}$ needs to be given a value (which may be the main levels of $\mathrm{RO}_{2}$ self- and cross-reaction rate constants in this study, $1 \times 10^{-13}$ and $1 \times 10^{-11} \mathrm{~cm}^{3}$ molecule ${ }^{-1} \mathrm{~s}^{-1}$, or other values depending on the $\mathrm{RO}_{2}$ type).

At the steady state, $P$ and $L$ are equal. For an ambient and/or chamber setting, $\mathrm{OH}, \mathrm{HO}_{2}, \mathrm{NO}, \mathrm{NO}_{2}$ and $\mathrm{OHR}$ VOC are often measured or known. In this case, simultaneously considering Eqs. (B1) and (B2) yields a quadratic equation of $\mathrm{RO}_{2}$ concentration (the only unknown). Then the generic $\mathrm{RO}_{2}$ concentration can be easily obtained by solving this equation:

$\mathrm{RO}_{2}=\left(-K+\sqrt{K^{2}+8 k_{\mathrm{RO}_{2}} \cdot \mathrm{OHR}_{\mathrm{VOC}} \cdot \mathrm{OH}}\right) /\left(4 k_{\mathrm{RO}_{2}}\right)$

where $K=k_{\mathrm{HO}_{2}} \mathrm{HO}_{2}+k_{\mathrm{NO}} \mathrm{NO}+k_{\mathrm{NO}_{2}} \mathrm{NO}_{2}+k_{\mathrm{OH}} \mathrm{OH}$. 
Supplement. The supplement related to this article is available online at: https://doi.org/10.5194/acp-19-813-2019-supplement.

Author contributions. ZP and JLJ designed the study. ZP performed most of the simulations, and JLT performed the GECKO-A simulations. JJO and GST provided advice on the organic peroxy radical chemistry. ZP, JJO, GST, and JLJ analyzed the results. ZP took the lead in writing the paper. All authors provided feedback on the paper.

Competing interests. The authors declare that they have no conflict of interest.

Acknowledgements. This work was partially supported by grants EPA STAR 83587701-0, NSF AGS-1740610, NSF AGS-1822664, NASA NNX15AT96G and DOE(BER/ASR) DE-SC0016559. We thank the following individuals for providing data from atmospheric field studies: Tran Nguyen and Jordan Krechmer (FIXCIT), William Brune (SOAS and ATom), Pedro Campuzano-Jost (ATom), Daun Jeong and Saewung Kim (GoAmazon), and Weiwei $\mathrm{Hu}$ (Beijing). We are also grateful to John Crounse, Joel Thornton, Paul Ziemann, Dwayne Heard, Paul Wennberg, Andrew Lambe and William Brune for useful discussions and Donna Sueper for her assistance in the development of the $\mathrm{RO}_{2}$ Fate Estimator. NCAR is sponsored by the National Science Foundation. The EPA has not reviewed this paper and thus no endorsement should be inferred.

Edited by: Dwayne Heard

Reviewed by: two anonymous referees

\section{References}

Assaf, E., Song, B., Tomas, A., Schoemaecker, C., and Fittschen, C.: Rate Constant of the Reaction between $\mathrm{CH}_{3} \mathrm{O}_{2}$ Radicals and OH Radicals Revisited, J. Phys. Chem. A, 120, 8923-8932, https://doi.org/10.1021/acs.jpca.6b07704, 2016.

Assaf, E., Tanaka, S., Kajii, Y., Schoemaecker, C., and Fittschen, C.: Rate constants of the reaction of $\mathrm{C} 2-\mathrm{C} 4$ peroxy radicals with $\mathrm{OH}$ radicals, Chem. Phys. Lett., 684, 245-249, https://doi.org/10.1016/j.cplett.2017.06.062, 2017a.

Assaf, E., Sheps, L., Whalley, L., Heard, D., Tomas, A., Schoemaecker, C., and Fittschen, C.: The Reaction between $\mathrm{CH}_{3} \mathrm{O}_{2}$ and $\mathrm{OH}$ Radicals: Product Yields and Atmospheric Implications, Environ. Sci. Technol., 51, 2170-2177, https://doi.org/10.1021/acs.est.6b06265, 2017b.

Assaf, E., Schoemaecker, C., Vereecken, L., and Fittschen, C.: Experimental and theoretical investigation of the reaction of $\mathrm{RO}_{2}$ radicals with $\mathrm{OH}$ radicals: Dependence of the $\mathrm{HO}_{2}$ yield on the size of the alkyl group, Int. J. Chem. Kinet., 50, 670-680, https://doi.org/10.1002/kin.21191, 2018.

Atkinson, R. and Arey, J.: Atmospheric degradation of volatile organic compounds, Chem. Rev., 103, 4605-4638, https://doi.org/10.1021/cr0206420, 2003.

Aumont, B., Szopa, S., and Madronich, S.: Modelling the evolution of organic carbon during its gas-phase tropospheric ox- idation: development of an explicit model based on a self generating approach, Atmos. Chem. Phys., 5, 2497-2517, https://doi.org/10.5194/acp-5-2497-2005, 2005.

Berndt, T., Scholz, W., Mentler, B., Fischer, L., Herrmann, H., Kulmala, M., and Hansel, A.: Accretion Product Formation from Self- and Cross-Reactions of $\mathrm{RO}_{2}$ Radicals in the Atmosphere, Angew. Chem. Int. Edit., 57, 3820-3824, https://doi.org/10.1002/anie.201710989, 2018.

Bossolasco, A., Faragó, E. P., Schoemaecker, C., and Fittschen, C.: Rate constant of the reaction between $\mathrm{CH}_{3} \mathrm{O}_{2}$ and $\mathrm{OH}$ radicals, Chem. Phys. Lett., 593, 7-13, https://doi.org/10.1016/j.cplett.2013.12.052, 2014.

Burkholder, J. B., Sander, S. P., Abbatt, J., Barker, J. R., Huie, R. E., Kolb, C. E., Kurylo, M. J., Orkin, V. L., Wilmouth, D. M., and Wine, P. H.: Chemical Kinetics and Photochemical Data for Use in Atmospheric Studies: Evaluation Number 18, Pasadena, CA, USA, available at: http://jpldataeval.jpl.nasa.gov/ (last access: 30 November 2018), 2015.

Carter, W. P. L., Cocker, D. R., Fitz, D. R., Malkina, I. L., Bumiller, K., Sauer, C. G., Pisano, J. T., Bufalino, C., and Song, C.: A new environmental chamber for evaluation of gas-phase chemical mechanisms and secondary aerosol formation, Atmos. Environ., 39, 7768-7788, https://doi.org/10.1016/j.atmosenv.2005.08.040, 2005.

Cocker, D. R., Flagan, R. C., and Seinfeld, J. H.: Stateof-the-Art Chamber Facility for Studying Atmospheric Aerosol Chemistry, Environ. Sci. Technol., 35, 2594-2601, https://doi.org/10.1021/es0019169, 2001.

Crounse, J. D., Nielsen, L. B., Jørgensen, S., Kjaergaard, H. G., and Wennberg, P. O.: Autoxidation of organic compounds in the atmosphere, J. Phys. Chem. Lett., 4, 3513-3520, https://doi.org/10.1021/jz4019207, 2013.

D’Ambro, E. L., Møller, K. H., Lopez-Hilfiker, F. D., Schobesberger, S., Liu, J., Shilling, J. E., Lee, B. H., Kjaergaard, H. G., and Thornton, J. A.: Isomerization of Second-Generation Isoprene Peroxy Radicals: Epoxide Formation and Implications for Secondary Organic Aerosol Yields, Environ. Sci. Technol., 51, 4978-4987, https://doi.org/10.1021/acs.est.7b00460, 2017.

Fittschen, C., Whalley, L. K., and Heard, D. E.: The reaction of $\mathrm{CH}_{3} \mathrm{O}_{2}$ radicals with $\mathrm{OH}$ radicals: a neglected sink for $\mathrm{CH}_{3} \mathrm{O}_{2}$ in the remote atmosphere, Environ. Sci. Technol., 48, 7700-7701, https://doi.org/10.1021/es502481q, 2014.

Fry, J. L., Draper, D. C., Zarzana, K. J., Campuzano-Jost, P., Day, D. A., Jimenez, J. L., Brown, S. S., Cohen, R. C., Kaser, L., Hansel, A., Cappellin, L., Karl, T., Hodzic Roux, A., Turnipseed, A., Cantrell, C., Lefer, B. L., and Grossberg, N.: Observations of gas- and aerosol-phase organic nitrates at BEACHON-RoMBAS 2011, Atmos. Chem. Phys., 13, 85858605, https://doi.org/10.5194/acp-13-8585-2013, 2013.

Hu, W., Palm, B. B., Day, D. A., Campuzano-Jost, P., Krechmer, J. E., Peng, Z., de Sá, S. S., Martin, S. T., Alexander, M. L., Baumann, K., Hacker, L., Kiendler-Scharr, A., Koss, A. R., de Gouw, J. A., Goldstein, A. H., Seco, R., Sjostedt, S. J., Park, J.-H., Guenther, A. B., Kim, S., Canonaco, F., Prévôt, A. S. H., Brune, W. H., and Jimenez, J. L.: Volatility and lifetime against $\mathrm{OH}$ heterogeneous reaction of ambient isoprene-epoxydiolsderived secondary organic aerosol (IEPOX-SOA), Atmos. Chem. Phys., 16, 11563-11580, https://doi.org/10.5194/acp-16-115632016, 2016. 
Huffman, J. A., Docherty, K. S., Aiken, A. C., Cubison, M. J., Ulbrich, I. M., DeCarlo, P. F., Sueper, D., Jayne, J. T., Worsnop, D. R., Ziemann, P. J., and Jimenez, J. L.: Chemically-resolved aerosol volatility measurements from two megacity field studies, Atmos. Chem. Phys., 9, 7161-7182, https://doi.org/10.5194/acp9-7161-2009, 2009.

Jørgensen, S., Knap, H. C., Otkjær, R. V, Jensen, A. M., Kjeldsen, M. L. H., Wennberg, P. O., and Kjaergaard, H. G.: Rapid Hydrogen Shift Scrambling in Hydroperoxy-Substituted Organic Peroxy Radicals, J. Phys. Chem. A, 120, 266-275, https://doi.org/10.1021/acs.jpca.5b06768, 2016.

Kalafut-Pettibone, A. J., Klems, J. P., Burgess, D. R., and McGivern, W. S.: Alkylperoxy radical photochemistry in organic aerosol formation processes, J. Phys. Chem. A, 117, 1414114150, https://doi.org/10.1021/jp4094996, 2013.

Kang, E., Root, M. J., Toohey, D. W., and Brune, W. H.: Introducing the concept of Potential Aerosol Mass (PAM), Atmos. Chem. Phys., 7, 5727-5744, https://doi.org/10.5194/acp-7-5727-2007, 2007.

Kang, E., Toohey, D. W., and Brune, W. H.: Dependence of SOA oxidation on organic aerosol mass concentration and $\mathrm{OH}$ exposure: experimental PAM chamber studies, Atmos. Chem. Phys., 11, 1837-1852, https://doi.org/10.5194/acp-11-1837-2011, 2011.

Karjalainen, P., Timonen, H., Saukko, E., Kuuluvainen, H., Saarikoski, S., Aakko-Saksa, P., Murtonen, T., Bloss, M., Dal Maso, M., Simonen, P., Ahlberg, E., Svenningsson, B., Brune, W. H., Hillamo, R., Keskinen, J., and Rönkkö, T.: Time-resolved characterization of primary particle emissions and secondary particle formation from a modern gasoline passenger car, Atmos. Chem. Phys., 16, 8559-8570, https://doi.org/10.5194/acp16-8559-2016, 2016.

Klems, J. P., Lippa, K. A., and McGivern, W. S.: Quantitative Evidence for Organic Peroxy Radical Photochemistry at $254 \mathrm{~nm}$, J. Phys. Chem. A, 119, 344-351, https://doi.org/10.1021/jp509165x, 2015.

Knap, H. C. and Jørgensen, S.: Rapid Hydrogen Shift Reactions in Acyl Peroxy Radicals, J. Phys. Chem. A, 121, 1470-1479, https://doi.org/10.1021/acs.jpca.6b12787, 2017.

Krechmer, J. E., Pagonis, D., Ziemann, P. J., and Jimenez, J. L.: Quantification of Gas-Wall Partitioning in Teflon Environmental Chambers Using Rapid Bursts of Low-Volatility Oxidized Species Generated in Situ, Environ. Sci. Technol., 50, $5757-$ 5765, https://doi.org/10.1021/acs.est.6b00606, 2016.

Lambe, A., Massoli, P., Zhang, X., Canagaratna, M., Nowak, J., Daube, C., Yan, C., Nie, W., Onasch, T., Jayne, J., Kolb, C., Davidovits, P., Worsnop, D., and Brune, W.: Controlled nitric oxide production via $\mathrm{O}\left({ }^{1} \mathrm{D}\right)+\mathrm{N}_{2} \mathrm{O}$ reactions for use in oxidation flow reactor studies, Atmos. Meas. Tech., 10, 2283-2298, https://doi.org/10.5194/amt-10-2283-2017, 2017.

Lambe, A. T. and Jimenez, J. L.: PAM Wiki: User Groups, available at: https://sites.google.com/site/pamwiki/user-groups, last access: 2 July 2018

Lambe, A. T., Ahern, A. T., Williams, L. R., Slowik, J. G., Wong, J. P. S., Abbatt, J. P. D., Brune, W. H., Ng, N. L., Wright, J. P., Croasdale, D. R., Worsnop, D. R., Davidovits, P., and Onasch, T. B.: Characterization of aerosol photooxidation flow reactors: heterogeneous oxidation, secondary organic aerosol formation and cloud condensation nuclei activity measurements,
Atmos. Meas. Tech., 4, 445-461, https://doi.org/10.5194/amt-4445-2011, 2011.

Lambe, A. T., Cappa, C. D., Massoli, P., Onasch, T. B., Forestieri, S. D., Martin, A. T., Cummings, M. J., Croasdale, D. R., Brune, W. H., Worsnop, D. R., and Davidovits, P.: Relationship between Oxidation Level and Optical Properties of Secondary Organic Aerosol, Environ. Sci. Technol., 47, 6349-6357, https://doi.org/10.1021/es401043j, 2013.

Lambe, A. T., Chhabra, P. S., Onasch, T. B., Brune, W. H., Hunter, J. F., Kroll, J. H., Cummings, M. J., Brogan, J. F., Parmar, Y., Worsnop, D. R., Kolb, C. E., and Davidovits, P.: Effect of oxidant concentration, exposure time, and seed particles on secondary organic aerosol chemical composition and yield, Atmos. Chem. Phys., 15, 3063-3075, https://doi.org/10.5194/acp15-3063-2015, 2015.

Levy II, H.: Normal atmosphere: large radical and formaldehyde concentrations predicted., Science, 173, 141-143, https://doi.org/10.1126/science.173.3992.141, 1971.

Li, R., Palm, B. B., Ortega, A. M., Hu, W., Peng, Z., Day, D. A., Knote, C., Brune, W. H., de Gouw, J., and Jimenez, J. L.: Modeling the radical chemistry in an Oxidation Flow Reactor (OFR): radical formation and recycling, sensitivities, and $\mathrm{OH}$ exposure estimation equation, J. Phys. Chem. A, 119, 4418-4432, https://doi.org/10.1021/jp509534k, 2015.

Lim, C. Y., Browne, E. C., Sugrue, R. A., and Kroll, J. H.: Rapid heterogeneous oxidation of organic coatings on submicron aerosols, Geophys. Res. Lett., 44, 2949-2957, https://doi.org/10.1002/2017GL072585, 2017.

Link, M. F., Friedman, B., Fulgham, R., Brophy, P., Galang, A., Jathar, S. H., Veres, P., Roberts, J. M., and Farmer, D. K.: Photochemical processing of diesel fuel emissions as a large secondary source of isocyanic acid (HNCO), Geophys. Res. Lett., 43, 40334041, https://doi.org/10.1002/2016GL068207, 2016.

Mao, J., Ren, X., Brune, W. H., Olson, J. R., Crawford, J. H., Fried, A., Huey, L. G., Cohen, R. C., Heikes, B., Singh, H. B., Blake, D. R., Sachse, G. W., Diskin, G. S., Hall, S. R., and Shetter, R. E.: Airborne measurement of $\mathrm{OH}$ reactivity during INTEX-B, Atmos. Chem. Phys., 9, 163-173, https://doi.org/10.5194/acp-9163-2009, 2009.

Martin, S. T., Artaxo, P., Machado, L. A. T., Manzi, A. O., Souza, R. A. F., Schumacher, C., Wang, J., Andreae, M. O., Barbosa, H. M. J., Fan, J., Fisch, G., Goldstein, A. H., Guenther, A., Jimenez, J. L., Pöschl, U., Silva Dias, M. A., Smith, J. N., and Wendisch, M.: Introduction: Observations and Modeling of the Green Ocean Amazon (GoAmazon2014/5), Atmos. Chem. Phys., 16, 47854797, https://doi.org/10.5194/acp-16-4785-2016, 2016.

Martin, S. T., Artaxo, P., Machado, L., Manzi, A. O., Souza, R. A. F., Schumacher, C., Wang, J., Biscaro, T., Brito, J., Calheiros, A., Jardine, K., Medeiros, A., Portela, B., De Sá, S. S., Adachi, K., Aiken, A. C., Alblbrecht, R., Alexander, L., Andreae, M. O., Barbosa, H. M. J., Buseck, P., Chand, D., Comstmstmstock, J. M., Day, D. A., Dubey, M., Fan, J., Fastst, J., Fisch, G., Fortner, E., Giangrande, S., Gilllles, M., Goldststein, A. H., Guenther, A., Hubbbbe, J., Jensen, M., Jimenez, J. L., Keutstsch, F. N., Kim, S., Kuang, C., Laskskin, A., McKinney, K., Mei, F., Millller, M., Nascimento, R., Pauliquevis, T., Pekour, M., Peres, J., Petäjä, T., Pöhlklker, C., Pöschl, U., Rizzo, L., Schmid, B., Shilllling, J. E., Silva Dias, M. A., Smith, J. N., Tomlmlinson, J. M., Tóta, J., and Wendisch, M.: The green ocean amazon experiment (GOAMA- 
ZON2014/5) observes pollution affecting gases, aerosols, clouds, and rainfall over the rain forest, B. Am. Meteorol. Soc., 98, 981997, https://doi.org/10.1175/BAMS-D-15-00221.1, 2017.

Matsunaga, A. and Ziemann, P. J.: Gas-Wall Partitioning of Organic Compounds in a Teflon Film Chamber and Potential Effects on Reaction Product and Aerosol Yield Measurements, Aerosol Sci. Tech., 44, 881-892, https://doi.org/10.1080/02786826.2010.501044, 2010.

Müller, J.-F., Liu, Z., Nguyen, V. S., Stavrakou, T., Harvey, J. N., and Peeters, J.: The reaction of methyl peroxy and hydroxyl radicals as a major source of atmospheric methanol, Nat. Commun., 7, 13213, https://doi.org/10.1038/ncomms13213, 2016.

Nault, B. A., Campuzano-Jost, P., Day, D. A., Schroder, J. C., Anderson, B., Beyersdorf, A. J., Blake, D. R., Brune, W. H., Choi, Y., Corr, C. A., de Gouw, J. A., Dibb, J., DiGangi, J. P., Diskin, G. S., Fried, A., Huey, L. G., Kim, M. J., Knote, C. J., Lamb, K. D., Lee, T., Park, T., Pusede, S. E., Scheuer, E., Thornhill, K. L., Woo, J.-H., and Jimenez, J. L.: Secondary organic aerosol production from local emissions dominates the organic aerosol budget over Seoul, South Korea, during KORUS-AQ, Atmos. Chem. Phys., 18, 17769-17800, https://doi.org/10.5194/acp-18-177692018, 2018.

Nel, A.: Air Pollution-Related Illness: Effects of Particles, Science, 308, 804-806, https://doi.org/10.1126/science.1108752, 2005.

Nguyen, T. B., Crounse, J. D., Schwantes, R. H., Teng, A. P., Bates, K. H., Zhang, X., St. Clair, J. M., Brune, W. H., Tyndall, G. S., Keutsch, F. N., Seinfeld, J. H., and Wennberg, P. O.: Overview of the Focused Isoprene eXperiment at the California Institute of Technology (FIXCIT): mechanistic chamber studies on the oxidation of biogenic compounds, Atmos. Chem. Phys., 14, 1353113549, https://doi.org/10.5194/acp-14-13531-2014, 2014.

Orlando, J. J. and Tyndall, G. S.: Laboratory studies of organic peroxy radical chemistry: an overview with emphasis on recent issues of atmospheric significance, Chem. Soc. Rev., 41, 62946317, https://doi.org/10.1039/c2cs35166h, 2012.

Ortega, A. M., Day, D. A., Cubison, M. J., Brune, W. H., Bon, D., de Gouw, J. A., and Jimenez, J. L.: Secondary organic aerosol formation and primary organic aerosol oxidation from biomassburning smoke in a flow reactor during FLAME-3, Atmos. Chem. Phys., 13, 11551-11571, https://doi.org/10.5194/acp-1311551-2013, 2013.

Ortega, A. M., Hayes, P. L., Peng, Z., Palm, B. B., Hu, W., Day, D. A., Li, R., Cubison, M. J., Brune, W. H., Graus, M., Warneke, C., Gilman, J. B., Kuster, W. C., de Gouw, J., GutiérrezMontes, C., and Jimenez, J. L.: Real-time measurements of secondary organic aerosol formation and aging from ambient air in an oxidation flow reactor in the Los Angeles area, Atmos. Chem. Phys., 16, 7411-7433, https://doi.org/10.5194/acp16-7411-2016, 2016.

Ortega, J., Turnipseed, A., Guenther, A. B., Karl, T. G., Day, D. A., Gochis, D., Huffman, J. A., Prenni, A. J., Levin, E. J. T., Kreidenweis, S. M., DeMott, P. J., Tobo, Y., Patton, E. G., Hodzic, A., Cui, Y. Y., Harley, P. C., Hornbrook, R. S., Apel, E. C., Monson, R. K., Eller, A. S. D., Greenberg, J. P., Barth, M. C., Campuzano-Jost, P., Palm, B. B., Jimenez, J. L., Aiken, A. C., Dubey, M. K., Geron, C., Offenberg, J., Ryan, M. G., Fornwalt, P. J., Pryor, S. C., Keutsch, F. N., DiGangi, J. P., Chan, A. W. H., Goldstein, A. H., Wolfe, G. M., Kim, S., Kaser, L., Schnitzhofer, R., Hansel, A., Cantrell, C. A., Mauldin, R. L., and Smith, J. N.:
Overview of the Manitou Experimental Forest Observatory: site description and selected science results from 2008 to 2013, Atmos. Chem. Phys., 14, 6345-6367, https://doi.org/10.5194/acp14-6345-2014, 2014.

Palm, B. B., Campuzano-Jost, P., Ortega, A. M., Day, D. A., Kaser, L., Jud, W., Karl, T., Hansel, A., Hunter, J. F., Cross, E. S., Kroll, J. H., Peng, Z., Brune, W. H., and Jimenez, J. L.: In situ secondary organic aerosol formation from ambient pine forest air using an oxidation flow reactor, Atmos. Chem. Phys., 16, 29432970, https://doi.org/10.5194/acp-16-2943-2016, 2016.

Palm, B. B., Campuzano-Jost, P., Day, D. A., Ortega, A. M., Fry, J. L., Brown, S. S., Zarzana, K. J., Dube, W., Wagner, N. L., Draper, D. C., Kaser, L., Jud, W., Karl, T., Hansel, A., GutiérrezMontes, C., and Jimenez, J. L.: Secondary organic aerosol formation from in situ $\mathrm{OH}, \mathrm{O}_{3}$, and $\mathrm{NO}_{3}$ oxidation of ambient forest air in an oxidation flow reactor, Atmos. Chem. Phys., 17, 53315354, https://doi.org/10.5194/acp-17-5331-2017, 2017.

Peng, Z. and Jimenez, J. L.: Modeling of the chemistry in oxidation flow reactors with high initial NO, Atmos. Chem. Phys., 17, 11991-12010, https://doi.org/10.5194/acp-17-11991-2017, 2017.

Peng, Z., Day, D. A., Stark, H., Li, R., Lee-Taylor, J., Palm, B. B., Brune, W. H., and Jimenez, J. L.: $\mathrm{HO}_{\mathrm{x}}$ radical chemistry in oxidation flow reactors with low-pressure mercury lamps systematically examined by modeling, Atmos. Meas. Tech., 8, 4863-4890, https://doi.org/10.5194/amt-8-4863-2015, 2015.

Peng, Z., Day, D. A., Ortega, A. M., Palm, B. B., Hu, W., Stark, H., Li, R., Tsigaridis, K., Brune, W. H., and Jimenez, J. L.: Non-OH chemistry in oxidation flow reactors for the study of atmospheric chemistry systematically examined by modeling, Atmos. Chem. Phys., 16, 4283-4305, https://doi.org/10.5194/acp16-4283-2016, 2016.

Peng, Z., Palm, B. B., Day, D. A., Talukdar, R. K., Hu, W., Lambe, A. T., Brune, W. H., and Jimenez, J. L.: Model Evaluation of New Techniques for Maintaining High-NO Conditions in Oxidation Flow Reactors for the Study of $\mathrm{OH}-$ Initiated Atmospheric Chemistry, ACS Earth Sp. Chem., 2, 7286, https://doi.org/10.1021/acsearthspacechem.7b00070, 2018.

Platt, S. M., El Haddad, I., Zardini, A. A., Clairotte, M., Astorga, C., Wolf, R., Slowik, J. G., Temime-Roussel, B., Marchand, N., Ježek, I., Drinovec, L., Mocnik, G., Möhler, O., Richter, R., Barmet, P., Bianchi, F., Baltensperger, U., and Prévôt, A. S. H.: Secondary organic aerosol formation from gasoline vehicle emissions in a new mobile environmental reaction chamber, Atmos. Chem. Phys., 13, 9141-9158, https://doi.org/10.5194/acp13-9141-2013, 2013.

Praske, E., Otkjær, R. V., Crounse, J. D., Hethcox, J. C., Stoltz, B. M., Kjaergaard, H. G., and Wennberg, P. O.: Atmospheric autoxidation is increasingly important in urban and suburban North America, P. Natl. Acad. Sci. USA, 115, 64-69, https://doi.org/10.1073/pnas.1715540115, 2018.

Presto, A. A., Huff Hartz, K. E., and Donahue, N. M.: Secondary Organic Aerosol Production from Terpene Ozonolysis. 1. Effect of UV Radiation, Environ. Sci. Technol., 39, 7036-7045, https://doi.org/10.1021/es050174m, 2005.

Richards-Henderson, N. K., Goldstein, A. H., and Wilson, K. R.: Large Enhancement in the Heterogeneous Oxidation Rate of Organic Aerosols by Hydroxyl Radicals in the Pres- 
ence of Nitric Oxide, J. Phys. Chem. Lett., 6, 4451-4455, https://doi.org/10.1021/acs.jpclett.5b02121, 2015.

Richards-Henderson, N. K., Goldstein, A. H., and Wilson, K. R.: Sulfur Dioxide Accelerates the Heterogeneous Oxidation Rate of Organic Aerosol by Hydroxyl Radicals, Environ. Sci. Technol., 50, 3554-3561, https://doi.org/10.1021/acs.est.5b05369, 2016.

Ryerson, T. B., Andrews, A. E., Angevine, W. M., Bates, T. S., Brock, C. A., Cairns, B., Cohen, R. C., Cooper, O. R., De Gouw, J. A., Fehsenfeld, F. C., Ferrare, R. A., Fischer, M. L., Flagan, R. C., Goldstein, A. H., Hair, J. W., Hardesty, R. M., Hostetler, C. A., Jimenez, J. L., Langford, A. O., McCauley, E., McKeen, S. A., Molina, L. T., Nenes, A., Oltmans, S. J., Parrish, D. D., Pederson, J. R., Pierce, R. B., Prather, K., Quinn, P. K., Seinfeld, J. H., Senff, C. J., Sorooshian, A., Stutz, J., Surratt, J. D., Trainer, M., Volkamer, R., Williams, E. J., and Wofsy, S. C.: The 2010 California Research at the Nexus of Air Quality and Climate Change (CalNex) field study, J. Geophys. Res.-Atmos., 118, 5830-5866, https://doi.org/10.1002/jgrd.50331, 2013.

Stocker, T. F., Qin, D., Plattner, G.-K., Tignor, M., Allen, S. K., Boschung, J., Nauels, A., Xia, Y., Bex, V., and Midgley, P. M.: Climate Change 2013 - The Physical Science Basis, edited by Intergovernmental Panel on Climate Change, Cambridge University Press, Cambridge, 2014.

Stone, D., Whalley, L. K., and Heard, D. E.: Tropospheric $\mathrm{OH}$ and $\mathrm{HO}_{2}$ radicals: field measurements and model comparisons, Chem. Soc. Rev., 41, 6348-6404, https://doi.org/10.1039/c2cs35140d, 2012.

Tkacik, D. S., Lambe, A. T., Jathar, S., Li, X., Presto, A. A., Zhao, Y., Blake, D., Meinardi, S., Jayne, J. T., Croteau, P. L., and Robinson, A. L.: Secondary Organic Aerosol Formation from in-Use Motor Vehicle Emissions Using a Potential Aerosol Mass Reactor, Environ. Sci. Technol., 48, 11235-11242, https://doi.org/10.1021/es502239v, 2014.
Wang, J., Doussin, J. F., Perrier, S., Perraudin, E., Katrib, Y., Pangui, E., and Picquet-Varrault, B.: Design of a new multi-phase experimental simulation chamber for atmospheric photosmog, aerosol and cloud chemistry research, Atmos. Meas. Tech., 4, 2465-2494, https://doi.org/10.5194/amt-4-2465-2011, 2011.

Wofsy, S. C., Apel, E., Blake, D. R., Brock, C. A., Brune, W. H., Bui, T. P., Daube, B. C., Dibb, J. E., Diskin, G. S., Elkiins, J. W., Froyd, K., Hall, S. R., Hanisco, T. F., Huey, L. G., Jimenez, J. L., McKain, K., Montzka, S. A., Ryerson, T. B., Schwarz, J. P., Stephens, B. B., Weinzierl, B., and Wennberg, P.: ATom: Merged Atmospheric Chemistry, Trace Gases, and Aerosols, Oak Ridge, Tennessee, USA, 2018.

Yan, C., Kocevska, S., and Krasnoperov, L. N.: Kinetics of the Reaction of $\mathrm{CH}_{3} \mathrm{O}_{2}$ Radicals with $\mathrm{OH}$ Studied over the 292526 K Temperature Range, J. Phys. Chem. A, 120, 6111-6121, https://doi.org/10.1021/acs.jpca.6b04213, 2016.

Zhang, X., Cappa, C. D., Jathar, S. H., McVay, R. C., Ensberg, J. J., Kleeman, M. J., and Seinfeld, J. H.: Influence of vapor wall loss in laboratory chambers on yields of secondary organic aerosol, P. Natl. Acad. Sci. USA, 111, 5802-5807, https://doi.org/10.1073/pnas.1404727111, 2014.

Ziemann, P. J. and Atkinson, R.: Kinetics, products, and mechanisms of secondary organic aerosol formation, Chem. Soc. Rev., 41, 6582-6605, https://doi.org/10.1039/c2cs35122f, 2012. 